\title{
Dissociative Water Adsorption on Gas-Phase Titanium Dioxide Cluster Anions Probed with Infrared Photodissociation Spectroscopy
}

\author{
Marissa L. Weichman' ${ }^{1}$ - Sreekanta Debnath ${ }^{2,3} \cdot$ John T. Kelly $^{3}$ (1) \\ Sandy Gewinner ${ }^{2} \cdot$ Wieland Schöllkopf $^{2}$ (1) Daniel M. Neumark ${ }^{1,4}$ (D) \\ Knut R. Asmis ${ }^{3}$ (D)
}

\begin{abstract}
Gas-phase complexes of water on small titanium oxide clusters are model systems to examine the molecularlevel mechanism of dissociative water adsorption at defect sites on bulk titania surfaces. Here, we report infrared photodissociation (IRPD) spectra for $\left[\left(\mathrm{TiO}_{2}\right)_{n}\left(\mathrm{D}_{2} \mathrm{O}_{m}\right)\right]^{-}$clusters with $n=2-4$ and $m=1-3$; the clusters are tagged with weakly-bound $\mathrm{D}_{2}$ so that only single photon absorption is required for photodissociation. Vibrational features are reported in the spectral windows of 400-1200 and 2600$3000 \mathrm{~cm}^{-1}$, capturing both fingerprint cluster modes and O-D stretching modes. The IRPD spectra are interpreted with the aid of $\omega \mathrm{B} 97 \mathrm{X}-\mathrm{D} /$ aug-cc-pVDZ density functional theory calculations. We conclusively assign the IRPD spectra of the $n=2, m=1,2$ and $n=3, m=1-3$ clusters to global minimum-energy structures containing dissociatively adsorbed water. We also provide insight into the more complicated spectroscopy of the $n=4$ clusters, which show
\end{abstract}

Electronic supplementary material The online version of this article (https://doi.org/10.1007/s11244-017-0863-4) contains supplementary material, which is available to authorized users.

Daniel M. Neumark

dneumark@berkeley.edu

Knut R. Asmis

knut.asmis@uni-leipzig.de

1 Department of Chemistry, University of California, Berkeley, CA 94720, USA

2 Fritz-Haber-Institut der Max-Plank-Gesellschaft, Faradayweg 4-6, 14195 Berlin, Germany

3 Wilhelm-Ostwald-Institut für Physikalische und Theoretische Chemie, Universität Leipzig, Linnéstrasse 2, 04103 Leipzig, Germany

4 Chemical Sciences Division, Lawrence Berkeley National Laboratory, Berkeley, CA 94720, USA possible contributions from a kinetically trapped reactive intermediate in addition to the global minimum-energy isomer. From this work, we can draw conclusions about the size dependence and site-specificity of $\left(\mathrm{TiO}_{2}\right)_{n}{ }^{-}$cluster reactivity.

Keywords Infrared photodissociation spectroscopy · Metal oxide clusters $\cdot$ Titanium dioxide $\cdot$ Dissociative water adsorption $\cdot$ Water splitting catalysis $\cdot$ Density functional theory

\section{Introduction}

Titanium dioxide $\left(\mathrm{TiO}_{2}\right)$ is an abundant, inexpensive, nontoxic, stable, and versatile semiconducting material with numerous applications in heterogeneous catalysis [1], photocatalysis [2-4], photovoltaic cells [5, 6], environmental pollutant degradation [7], trace gas sensing, and as a white pigment. $\mathrm{TiO}_{2}$ is perhaps most notable as the world's most widely studied photocatalyst $[8,9]$. Since Fujishima and Honda's 1972 discovery of photocatalytic water splitting and $\mathrm{H}_{2}$ evolution on a $\mathrm{TiO}_{2}$ electrode [10], extensive work has been done to develop, characterize, and optimize $\mathrm{TiO}_{2}$-based technologies for sustainable conversion of sunlight into chemical hydrogen fuel [11, 12]. However, reaching a detailed understanding of the chemical mechanisms of hydrolysis and $\mathrm{H}_{2}$ evolution on $\mathrm{TiO}_{2}$ surfaces and nanostructures remains an unsolved problem. In this paper, we explore water splitting on $\mathrm{TiO}_{2}$ in molecular detail by measuring vibrational spectra of cryogenically-cooled $\left[\left(\mathrm{TiO}_{2}\right)_{n}\left(\mathrm{D}_{2} \mathrm{O}\right)_{m}\right]^{-}$cluster anions. This work stands as a follow-up to our prior characterization of the bare $\left(\mathrm{TiO}_{2}\right)_{n}{ }^{-}$anions [13] as we move towards more explicit cluster-based models of catalytic reaction mechanisms. 
There is an enormous body of experimental and theoretical work on the interaction of water with titanium dioxide surfaces. Wetting of the $\mathrm{TiO}_{2}$ surface is necessarily the first step of any water splitting reaction pathway, yet the extent to which water adsorbs molecularly or dissociatively on $\mathrm{TiO}_{2}$ remains controversial [14-16]. Experimental studies show that water adsorption trends are distinct for different facets of rutile and anatase $\mathrm{TiO}_{2}$ and depend heavily on water surface coverage and the presence of defect sites [17-28]. Further studies have found that $\mathrm{TiO}_{2}$ photoexcitation can enhance the initial dissociative adsorption of water [28, 29]. Overall, dissociative water adsorption appears to be a minor pathway on defect-free $\mathrm{TiO}_{2}$ surfaces, but is more likely to occur at defect sites, including steps [27, 30], ridges [31], and particularly oxygen vacancies [17, 18, 21-25, 32].

In a bulk experiment, it is challenging to prepare a surface with reproducible, well-characterized defect sites, let alone probe the reaction mechanism at a specific catalytic center. Small gas-phase clusters can serve as model systems of the local behavior and reactivity of a bulk metal oxide [33, 34]. Clusters exhibit varied geometries and stoichiometries, with under-coordinated atoms and dangling moieties that mimic reactive point defects on a bulk surface [35, 36]. Size-selected clusters can be complexed with a well-defined number of substrate molecules, allowing for the systematic characterization of how cluster size, stoichiometry, and local structure affect reactivity [37-40]. These systems are also tractable for simulation with high level quantum chemistry calculations, allowing for analysis of geometries and reaction mechanisms with clarity not available in bulk studies [41].

While there is a growing body of work on the gas-phase spectroscopy of bare titanium dioxide clusters [13, 42-46], studies probing their interactions with water are more sparse. Early work from the Castleman group reported on the mass spectrum of the water-solvated $\mathrm{TiO}^{+}$cation [47]. Yin and Bernstein [38] reacted neutral $\mathrm{Ti}_{2} \mathrm{O}_{4}$ and $\mathrm{Ti}_{2} \mathrm{O}_{5}$ clusters with water and found oxidation of water to hydrogen peroxide on $\mathrm{Ti}_{2} \mathrm{O}_{5}$ after irradiation with visible light. Zheng and coworkers reported infrared action spectra of $\left[\mathrm{TiO}\left(\mathrm{H}_{2} \mathrm{O}\right)_{m}\right]^{+}[48]$ and anion photoelectron spectra of $\left[\mathrm{TiO}_{2}\left(\mathrm{H}_{2} \mathrm{O}\right)_{m}\right]^{-}[49]$, and ascribe both sets of measurements to structures involving dissociatively adsorbed water molecules.

Several theoretical groups have reported calculations of molecular and dissociative water adsorption and water splitting on small $\left(\mathrm{TiO}_{2}\right)_{n}$ clusters [50-56]; others have studied these interactions on larger $\mathrm{TiO}_{2}$ nanostructures [57-60]. The most thorough body of work comes from calculations by Dixon and coworkers [61-63] regarding water adsorption, hydrolysis, and $\mathrm{H}_{2} / \mathrm{O}_{2}$ evolution on small neutral titanium dioxide clusters. Most recently, these authors used a hybrid genetic algorithm to rigorously identify the lowest-energy structures for the neutral $\left[\left(\mathrm{TiO}_{2}\right)_{n}\left(\mathrm{H}_{2} \mathrm{O}\right)_{m}\right]$ ( $n \leq 4 ; m \leq 2 n)$ clusters [63]. Geometry optimization and single-point energy calculations were carried out with the B3LYP and CCSD(T) methods, respectively.

Dixon and coworkers predict that the bare $\left(\mathrm{TiO}_{2}\right)_{n}$ ( $n=2-4)$ clusters dissociatively adsorb the first two water molecules, forming minimum-energy structures with two and four terminal $\mathrm{Ti}-\mathrm{OH}$ groups after the first and second waters react, respectively [63]. $\left(\mathrm{TiO}_{2}\right)_{3}$ can go on to dissociate a third water, forming a structure with six terminal hydroxyl groups. Many theoretical studies [51, 53, $61,63]$ note that after the initial adsorption of water on a bare $\left(\mathrm{TiO}_{2}\right)_{n}$ cluster, at least two $\mathrm{H}$-atom transfer steps are required in order to form the $\left[\left(\mathrm{TiO}_{2}\right)_{n}\left(\mathrm{H}_{2} \mathrm{O}\right)_{m}\right]$ global minimum structure. Typically, the reaction proceeds through an intermediate containing a bridging $\mathrm{Ti}-(\mathrm{OH})-\mathrm{Ti}$ moiety before reaching the final structure containing only terminal $\mathrm{OH}$ moieties $[53,61]$. Water dissociation is preferred until all $\mathrm{Ti}$ atoms are saturated with coordination numbers of four; subsequent water molecules added beyond this hydrolysis limit adsorb molecularly [63].

Vibrational action spectroscopy has proved to be an excellent method to characterize the structure of gas-phase ions $[64,65]$, and has been particularly illuminating for the study of transition metal oxide clusters, which demonstrate complex electronic structure and many low-lying structural isomers [13, 66, 67]. Most recently, this technique has been adapted to illuminate site-specific water dissociation on $\mathrm{Al}_{3} \mathrm{O}_{4}{ }^{+}$[40].

Here, we present infrared photodissociation (IRPD) spectra of messenger-tagged titanium dioxide-water cluster anions $\left[\left(\mathrm{TiO}_{2}\right)_{n}\left(\mathrm{D}_{2} \mathrm{O}\right)_{m}\right]^{-}$with $n=2-4$ and $m=1-3$ in the fingerprint (400-1200 $\left.\mathrm{cm}^{-1}\right)$ and O-D stretching (2600-3000 $\mathrm{cm}^{-1}$ ) spectral regions. We assign structures by comparison to harmonic IR spectra of low-energy isomers from density functional theory (DFT) calculations. For all cluster sizes, we find evidence for dissociative water adsorption and satisfactory agreement with the predicted spectrum of the global minimum-energy structure. Energetically higher-lying structural isomers may also contribute to the spectra of the $n=4$ clusters, possibly due to kinetic trapping of these species during intramolecular H-atom transfer. We identify characteristic spectral regions for particular structural motifs and show that the loss of vibrational structure in the $\mathrm{Ti}-\mathrm{O}$ stretching region serves as the most conclusive signature of dissociative water adsorption on $\left(\mathrm{TiO}_{2}\right)_{n}{ }^{-}$. These results allow us to draw conclusions about the size- and site-dependent reactivity of $\left(\mathrm{TiO}_{2}\right)_{n}{ }^{-}$anions, which we discuss in the context of water splitting on bulk $\mathrm{TiO}_{2}$ defect sites. 


\section{Experimental Methods}

IRPD experiments are carried out using an ion trap tandem mass spectrometer [68-70] and intense, widely tunable IR radiation from the Fritz Haber Institute free electron laser (FHI-FEL) [71].

$\left[\left(\mathrm{TiO}_{2}\right)_{n}\left(\mathrm{D}_{2} \mathrm{O}\right)_{m}\right]^{-}$clusters are prepared in a dual gas channel pulsed laser vaporization source [40], based on the fast flow cluster reactor pioneered by Smalley and coworkers [72]. A frequency-doubled Nd:YAG laser operated at $50 \mathrm{~Hz}$ is focused onto a rotating titanium rod, with a pulse energy of 15-20 mJ. The resulting plasma is quenched with a pulse of $0.25 \% \mathrm{O}_{2}$ in helium from a General Valve. $\left(\mathrm{TiO}_{2}\right)_{n}{ }^{-}$clusters are formed during expansion through a clustering channel downstream from the rod. After a short time delay, a second General Valve, backed by 2 bar of helium passed through a $\mathrm{D}_{2} \mathrm{O}$ bubbler, sends a pulse of gas into the final stage of the clustering channel to form the desired $\left[\left(\mathrm{TiO}_{2}\right)_{n}\left(\mathrm{D}_{2} \mathrm{O}\right)_{m}\right]^{-}$clusters.

After formation, the beam of $\left[\left(\mathrm{TiO}_{2}\right)_{n}\left(\mathrm{D}_{2} \mathrm{O}\right)_{m}\right]^{-}$anions passes through a skimmer and into an RF decapole ion guide filled with He to aid in beam collimation and collisional thermalization to room temperature. The ions then enter a quadrupole mass filter, which is tuned to transmit only clusters of the desired $\left[\left({ }^{48} \mathrm{Ti}^{16} \mathrm{O}_{2}\right)_{n}\left(\mathrm{D}_{2}{ }^{16} \mathrm{O}\right)_{m}\right]^{-}$mass/charge ratio. Quadrupole mass spectra of $\left(\mathrm{TiO}_{2}\right)_{n}{ }^{-}$anions with and without $\mathrm{D}_{2} \mathrm{O}$ vapor added to the clustering channel are shown in Fig. S1.

The anion beam is then steered and focused into a cryogenic RF ring-electrode ion trap [68], which is filled continuously with pure $\mathrm{D}_{2}$ buffer gas and held at $15 \mathrm{~K}$. Anions are accumulated in the trap over ten laser vaporization source cycles, where they were thermalized and messenger-tagged [73] through collisions with the $\mathrm{D}_{2}$ buffer gas. The trap temperature and buffer gas concentration were chosen to tag around $10 \%$ of anions with a single $\mathrm{D}_{2}$ molecule. Clusters are extracted from the ion trap every $200 \mathrm{~ms}$ and are spatially and temporally focused into the extraction region of an orthogonally mounted time-of-flight (TOF) mass spectrometer, where they are irradiated with a counter-propagating IR macropulse from the FHI-FEL. All tagged and bare anions are then accelerated towards an MCP detector and their TOF intensities are monitored as the FEL wavelength is scanned.

The FHI-FEL can produce radiation in the range $210-3000 \mathrm{~cm}^{-1}$ with a spectral bandwidth better than $0.5 \%$ fwhm of the photon energy [71]. In this experiment, we use two operating regions of the FEL: the $440-1200 \mathrm{~cm}^{-1}$ range produced with a $26 \mathrm{MeV}$ electron beam, and the $2600-3000 \mathrm{~cm}^{-1}$ range produced with a $43.5 \mathrm{MeV}$ electron beam. In the lower energy region, the FHI-FEL has a spectral bandwidth ranging from $\sim 2 \mathrm{~cm}^{-1}$ fwhm at $450 \mathrm{~cm}^{-1}$ to $\sim 7 \mathrm{~cm}^{-1}$ fwhm at $1200 \mathrm{~cm}^{-1}$. In the higher energy region, the bandwidth is $15-20 \mathrm{~cm}^{-1}$. Typical macropulse energies are $30-40 \mathrm{~mJ}$ in both regions. For each spectrum, the photon energy is stepped in $3 \mathrm{~cm}^{-1}$ increments, though a $5 \mathrm{~cm}^{-1}$ step is typically used in the higher energy region where the FEL bandwidth is larger. For each step, 50-100 TOF traces are acquired and averaged, depending on the signalto-noise level for a given system. Attenuated laser pulses using 5-50\% of the full FEL power are employed as necessary to ensure operation within a linear absorption regime and to avoid saturating transitions. The IRPD cross section, $\sigma_{\text {IRPD }}$, is calculated from the TOF spectra by normalizing the relative abundance of parent and fragment ions to the laser fluence at each photon energy [69, 70].

$\mathrm{D}_{2} \mathrm{O}$ loss is also observed from some untagged $\left[\left(\mathrm{TiO}_{2}\right)_{n}\left(\mathrm{D}_{2} \mathrm{O}\right)_{m}\right]^{-}$clusters when irradiated with the full FEL power. These dissociation channels involve infrared multiple photon dissociation (IRMPD) processes and are negligible with the attenuated laser pulses used to acquire the $\mathrm{D}_{2}$-tagged IRPD spectra.

\section{Calculations}

The relative energies, optimized geometries, harmonic vibrational frequencies, and IR intensities of the energetically lowest-lying $\left[\left(\mathrm{TiO}_{2}\right)_{n}\left(\mathrm{D}_{2} \mathrm{O}\right)_{m}\right]^{-}$isomers were investigated using DFT. We use the range-separated hybrid $\omega \mathrm{B} 97 \mathrm{X}-\mathrm{D}$ functional [74] which includes dispersion interactions and has been shown to perform well for geometry optimization of transition metal compounds [75]. The aug-cc-pVDZ (aVDZ) basis set is used for all atoms, with full treatment of all electrons. All DFT calculations were carried out using Gaussian 09, revision C01 [76].

Low-lying $\left[\left(\mathrm{TiO}_{2}\right)_{n}\left(\mathrm{D}_{2} \mathrm{O}\right)_{m}\right]^{-}$structures were adapted largely from the recent theoretical work by Dixon and coworkers [63] who used a genetic algorithm to identify the most stable neutral $\left[\left(\mathrm{TiO}_{2}\right)_{n}\left(\mathrm{H}_{2} \mathrm{O}\right)_{m}\right]$ structures. We considered all low-lying structures these authors proposed as well as additional $n=4$ cluster structures involving bridging hydroxyl groups [53, 61]. The literature geometries were reoptimized with spin-unrestricted $\omega \mathrm{B} 97 \mathrm{X}-\mathrm{D} / \mathrm{aVDZ}$ calculations as doublet anions. All optimizations were carried out without symmetry restrictions. We report all calculated $\left[\left(\mathrm{TiO}_{2}\right)_{n}\left(\mathrm{D}_{2} \mathrm{O}\right)_{m}\right]^{-}$structures lying within $150 \mathrm{~kJ} / \mathrm{mol}$ of the lowest-energy isomer, as well as some higher-lying $n=4$ structures containing molecularly adsorbed water. Complete lists of isomer energetics, harmonic vibrational frequencies above $400 \mathrm{~cm}^{-1}$, and optimized geometries can be found in the Supporting Information (SI) in Tables S1-S14. We also report the binding energy of $\mathrm{D}_{2} \mathrm{O}$ to $\left[\left(\mathrm{TiO}_{2}\right)_{n}\left(\mathrm{D}_{2} \mathrm{O}\right)_{m}\right]^{-}$, given by the energy difference relative to the global minimum-energy $\left[\left(\mathrm{TiO}_{2}\right)_{n}\left(\mathrm{D}_{2} \mathrm{O}\right)_{m-1}\right]^{-}$structure plus a free $\mathrm{D}_{2} \mathrm{O}$ molecule. 


\section{Results and Discussion}

Experimental IRPD spectra of the $\mathrm{D}_{2}$-tagged $\left[\left(\mathrm{TiO}_{2}\right)_{n}\left(\mathrm{D}_{2} \mathrm{O}\right)_{m}\right]^{-}$clusters are shown in Fig. 1. IRPD spectra from our earlier study [13] of clusters with $n=3,4$ and $m=0$ are also plotted in Fig. 1. An IRPD spectrum could not

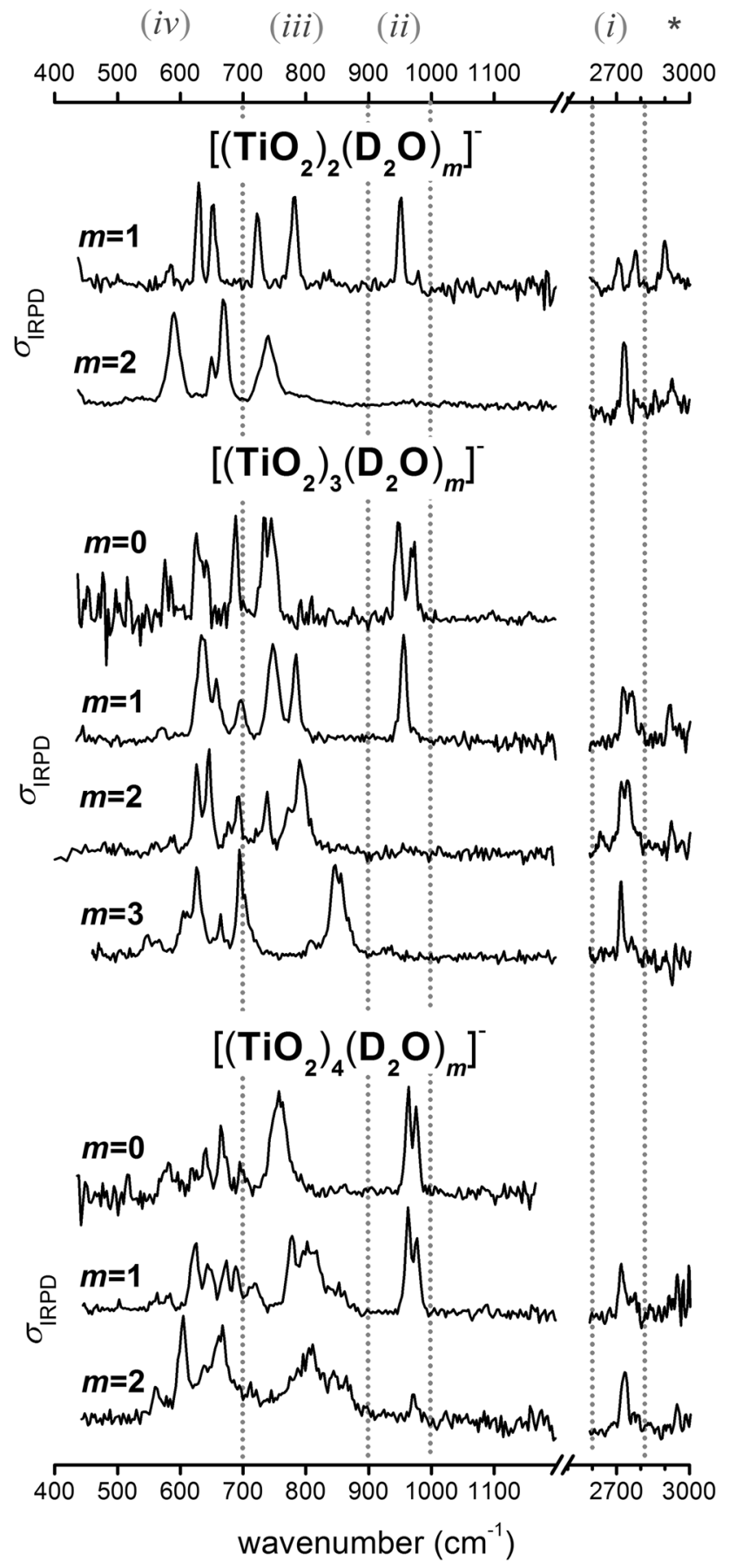

Fig. 1 Experimental IRPD spectra of $\mathrm{D}_{2}$-tagged $\left[\left(\mathrm{TiO}_{2}\right)_{n}\left(\mathrm{D}_{2} \mathrm{O}\right)_{m}\right]^{-}$ clusters. Characteristic spectral regions are marked with gray dashed lines. The region marked with an asterisk contains the $\mathrm{D}_{2}$ tag stretching mode. The $m=0$ spectra are reproduced from our prior work [13] be acquired for $\mathrm{D}_{2}$-tagged $\left(\mathrm{TiO}_{2}\right)_{2}{ }^{-}$, as it is known to react with molecular hydrogen rather than form a physisorbed complex [46, 77]. The global minimum-energy structures for the bare clusters identified in previous work [13, 46, 78] are reproduced in Fig. 2. The lowest-lying structures of $\left[\left(\mathrm{TiO}_{2}\right)_{n}\left(\mathrm{D}_{2} \mathrm{O}\right)_{m}\right]^{-}(m \geq 1)$ are shown in Fig. 3, with relative $\omega \mathrm{B} 97 \mathrm{X}-\mathrm{D} / \mathrm{aVDZ}$ energies given in $\mathrm{kJ} / \mathrm{mol}$. Note that the IR photon energies in Fig. 1 are well above the binding energy of the $\mathrm{D}_{2}$ tag, which is calculated to be only $1.4 \mathrm{~kJ} /$ mol $\left(120 \mathrm{~cm}^{-1}\right)$ for the 2-1-a structure of $\left[\left(\mathrm{TiO}_{2}\right)_{n}\left(\mathrm{D}_{2} \mathrm{O}\right)\right]^{-}$. Hence, absorption of only a single photon is required for photodissociation (i.e. $\mathrm{D}_{2}$ loss) to occur.

Additional IRMPD spectra corresponding to loss of one or two $\mathrm{D}_{2} \mathrm{O}$ molecules are shown in Fig. $\mathrm{S} 2$ for some untagged $\left[\left(\mathrm{TiO}_{2}\right)_{n}\left(\mathrm{D}_{2} \mathrm{O}\right)_{m}\right]^{-}$clusters. Binding energies of $\mathrm{D}_{2} \mathrm{O}$ to these $\left[\left(\mathrm{TiO}_{2}\right)_{n}\left(\mathrm{D}_{2} \mathrm{O}\right)_{m}\right]^{-}$clusters can exceed $300 \mathrm{~kJ} /$ mol (see Tables S1-S7), requiring the absorption of tens of $1000 \mathrm{~cm}^{-1}$ photons for dissociation to occur. IRMPD spectra are therefore more difficult to interpret than their IRPD counterparts as the observed fragment ion yields do not directly correspond to the calculated linear IR intensities. Moreover, some IR active vibrational modes can be transparent in IRMPD experiments [79]. Despite these caveats, the $\mathrm{D}_{2}$-loss and $\mathrm{D}_{2} \mathrm{O}$-loss spectra are similar for the clusters with $n=2,3$, but do show some interesting differences for the $n=4$ clusters.

Simulated IR spectra derived from unscaled DFT harmonic vibrational frequencies and IR intensities are compared to the experimental IRPD results in Figs. 4, 5, 6, 7. Simulations are plotted both as stick spectra (red) and as traces convoluted with a $10 \mathrm{~cm}^{-1}$ fwhm Gaussian lineshape function (blue). Based on the comparison of the IRPD and DFT spectra, we can classify four general IR absorption regions, as indicated in Fig. 1. Region (i) from 2600 to $2800 \mathrm{~cm}^{-1}$ and region (ii) from 900 to $1000 \mathrm{~cm}^{-1}$ are

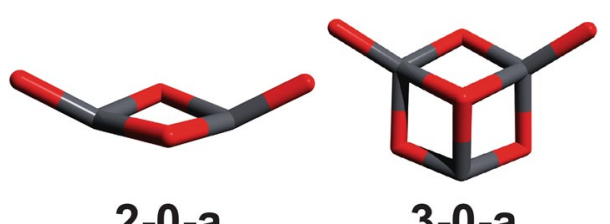

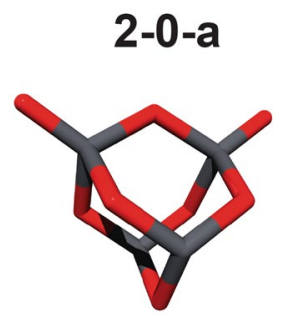

4-0-a

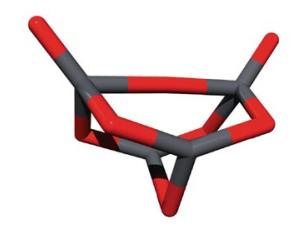

4-0-b
Fig. 2 Low-lying isomers of $\left(\mathrm{TiO}_{2}\right)_{n}{ }^{-}, n=2-4$ clusters identified in prior work [13, 46, 78]. Atoms in dark gray represent Ti, atoms in red represent $\mathrm{O}$ 

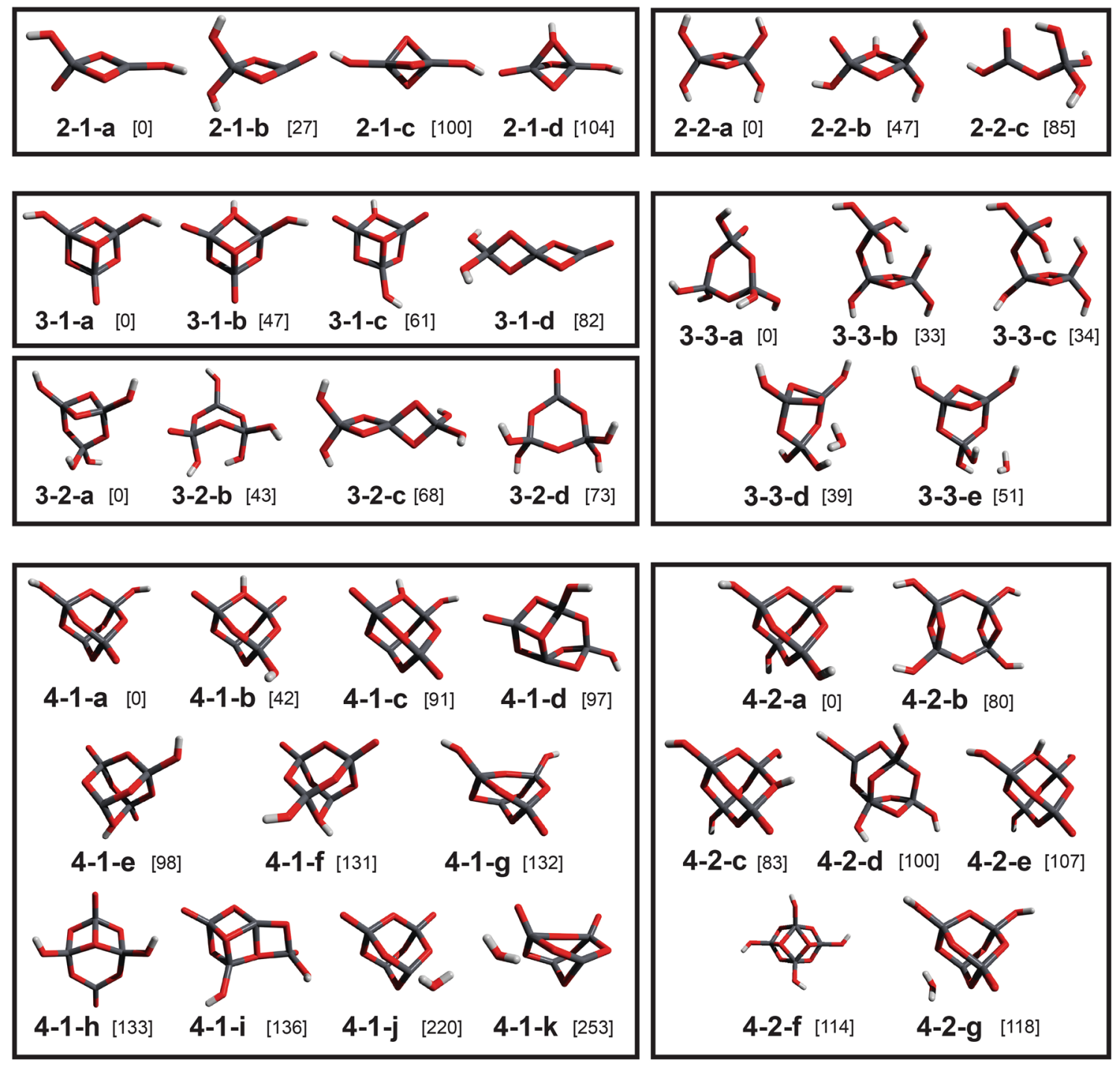

Fig. $3 \omega \mathrm{B} 97 \mathrm{X}-\mathrm{D} / \mathrm{aVDZ}$ minimum-energy structures and relative energies $(\mathrm{kJ} / \mathrm{mol})$ of energetically low-lying isomers of doublet $\left[\left(\mathrm{TiO}_{2}\right)_{\mathrm{n}}\left(\mathrm{D}_{2} \mathrm{O}\right)_{\mathrm{m}}\right]^{-}$cluster anions. Atoms in dark gray represent $\mathrm{Ti}$, atoms in red represent $\mathrm{O}$, and atoms in light gray represent $\mathrm{H}$

uniquely associated with $\mathrm{O}-\mathrm{D}$ stretching and terminal Ti-O stretching modes, respectively. Region (iii) from 700 to $900 \mathrm{~cm}^{-1}$ is largely associated with Ti-O-Ti bridge stretching modes. Ti-O-Ti bridge motion also couples with Ti-O-D bending and stretching modes, which tend to fall below $700 \mathrm{~cm}^{-1}$ in region (iv), along with more delocalized wagging, bending, rocking, and ring breathing modes. Dixon and coworkers $[61,63]$ have also reported harmonic vibrational frequencies and intensities and identified similar characteristic spectral regions for the neutral $\left[\left(\mathrm{TiO}_{2}\right)_{n}\left(\mathrm{H}_{2} \mathrm{O}\right)_{m}\right]$ clusters.

For $n=2,3$, the simulated IR spectra of the minimumenergy structures are in reasonably good agreement with the experimental spectra; the assignments for the spectra of the $n=4$ structures prove more complex. The experimental IRPD peak positions are listed alongside the calculated vibrational frequencies of the best-fit cluster structures in Tables 1, 2 and 3. The $\omega \mathrm{B} 97 \mathrm{X}-\mathrm{D} / \mathrm{aVDZ}$ frequencies of these best-fit simulations are generally higher than those observed experimentally, yielding scaling factors of $0.94-0.95$ in regions (i) and (ii) and a range of 0.95-1.02 in regions (iii) and (iv). Note that this is in contrast to the BP86/6-311+G* calculations in our prior work [13], which produced frequencies typically lower than the experimental values. These results are in reasonable accordance with the literature-recommended scale factors for these functionals [80].

Most of the IRPD spectra of the tagged clusters studied here also exhibit a $\mathrm{D}_{2}$ stretching feature in the 2900-2950 $\mathrm{cm}^{-1}$ range, marked with an asterisk in Fig. 1. While the $D_{2}$ stretch is IR forbidden in free $D_{2}$, it appears weakly here due to polarizing interactions with $\left[\left(\mathrm{TiO}_{2}\right)_{n}\left(\mathrm{D}_{2} \mathrm{O}\right)_{m}\right]^{-}$and is correspondingly red-shifted from 


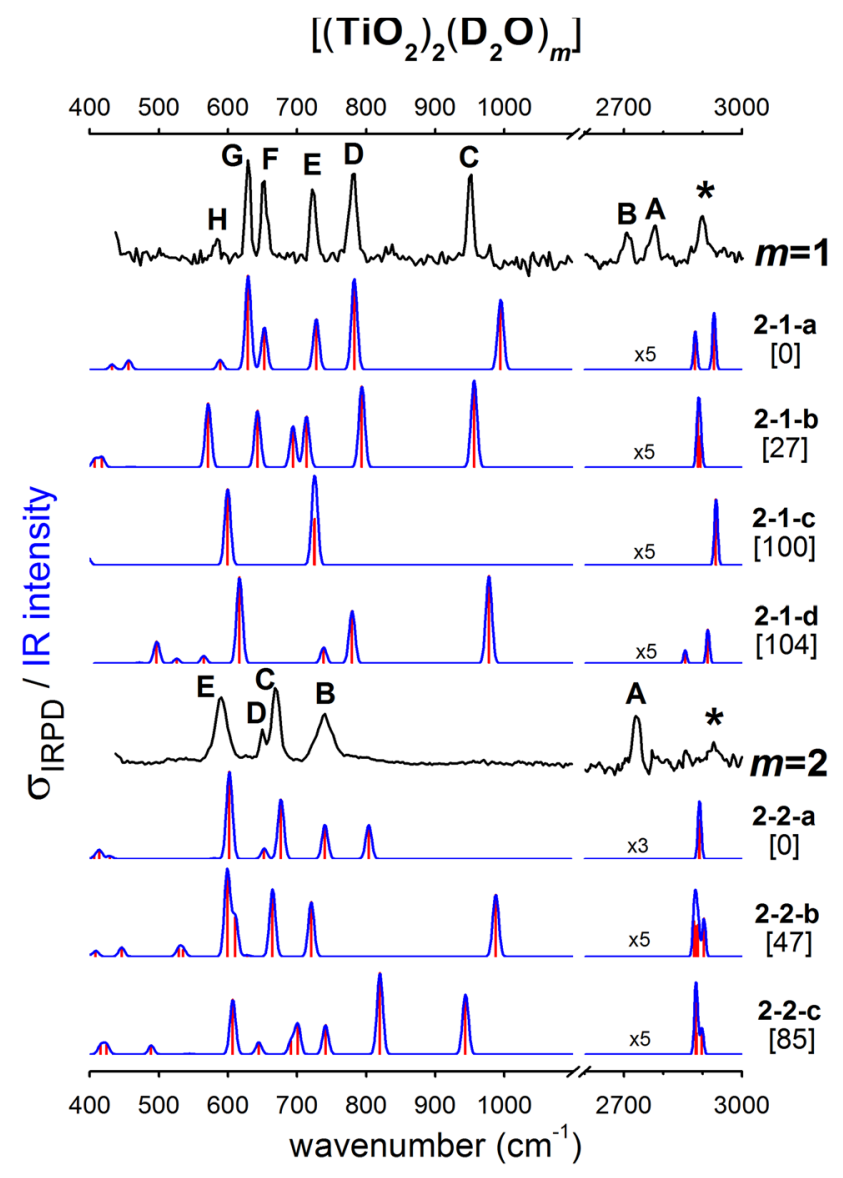

Fig. 4 Experimental IRPD spectra (black) of $\mathrm{D}_{2}$-tagged $\left[\left(\mathrm{TiO}_{2}\right)_{2}\left(\mathrm{D}_{2} \mathrm{O}\right)_{m}\right]^{-}$, simulated unscaled linear IR absorption spectra plotted with sticks (red) and a $10 \mathrm{~cm}^{-1}$ fwhm Gaussian convolution (blue), and relative energies $(\mathrm{kJ} / \mathrm{mol})$ of the predicted lowest-lying isomers at the $\omega \mathrm{B} 97 \mathrm{X}-\mathrm{D} / \mathrm{aVDZ}$ level of theory

the fundamental transition at $2994 \mathrm{~cm}^{-1}[81]$ in free $\mathrm{D}_{2}$. The observation of these features provides additional confirmation that the tag molecules are weakly molecularly adsorbed, rather than (dissociatively) chemisorbed.

We now provide more thorough analyses of the experimental and theoretical results for each of the $\left[\left(\mathrm{TiO}_{2}\right)_{n}\left(\mathrm{D}_{2} \mathrm{O}\right)_{m}\right]^{-}$clusters.

\section{1 $\left[\left(\mathrm{TiO}_{2}\right)_{2}\left(\mathrm{D}_{2} \mathrm{O}\right)_{m}\right]^{-}$}

The experimental IRPD spectrum for $\left[\left(\mathrm{TiO}_{2}\right)_{2}\left(\mathrm{D}_{2} \mathrm{O}\right)\right]^{-}$(Fig. 1) shows a pair of vibrational features in the $\mathrm{O}-\mathrm{D}$ stretching region (i), one strong peak in the $\mathrm{Ti}-\mathrm{O}$ stretching region (ii), and four strong features spanning regions (iii) and (iv). The spectrum simplifies with the addition of a second $\mathrm{D}_{2} \mathrm{O}$, with only one vibrational feature in region (i) and no features in region (ii).

The global minimum-energy structure of bare $\left(\mathrm{TiO}_{2}\right)_{2}{ }^{-}$, 2-0-a (Fig. 2), has $C_{2 v}$ symmetry with the unpaired

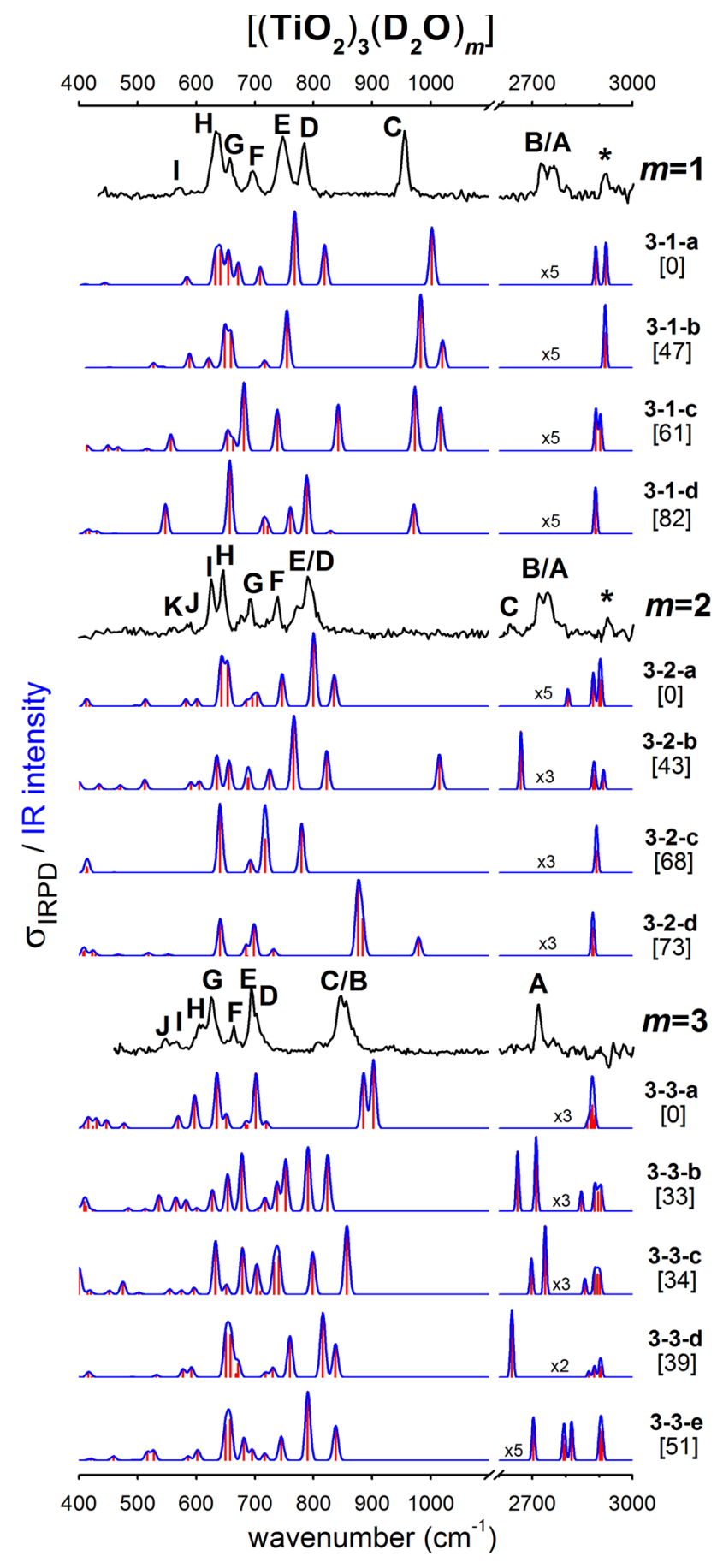

Fig. 5 Experimental IRPD spectra (black) of $\mathrm{D}_{2}$-tagged $\left[\left(\mathrm{TiO}_{2}\right)_{3}\left(\mathrm{D}_{2} \mathrm{O}\right)_{m}\right]^{-}$, simulated unscaled linear IR absorption spectra plotted with sticks (red) and a $10 \mathrm{~cm}^{-1}$ fwhm Gaussian convolution (blue), and relative energies $(\mathrm{kJ} / \mathrm{mol})$ of the predicted lowest-lying isomers at the $\omega \mathrm{B} 97 \mathrm{X}-\mathrm{D} / \mathrm{aVDZ}$ level of theory

electron delocalized over both Ti atoms [46, 78]. Upon dissociative adsorption of one $\mathrm{D}_{2} \mathrm{O}$ on $\mathbf{2 - 0 - a}$, two low energy structures of $C_{1}$ symmetry, 2-1-a and 2-1-b (Fig. 3), are obtained. Structure 2-1-b lies $27 \mathrm{~kJ} / \mathrm{mol}$ higher in energy 


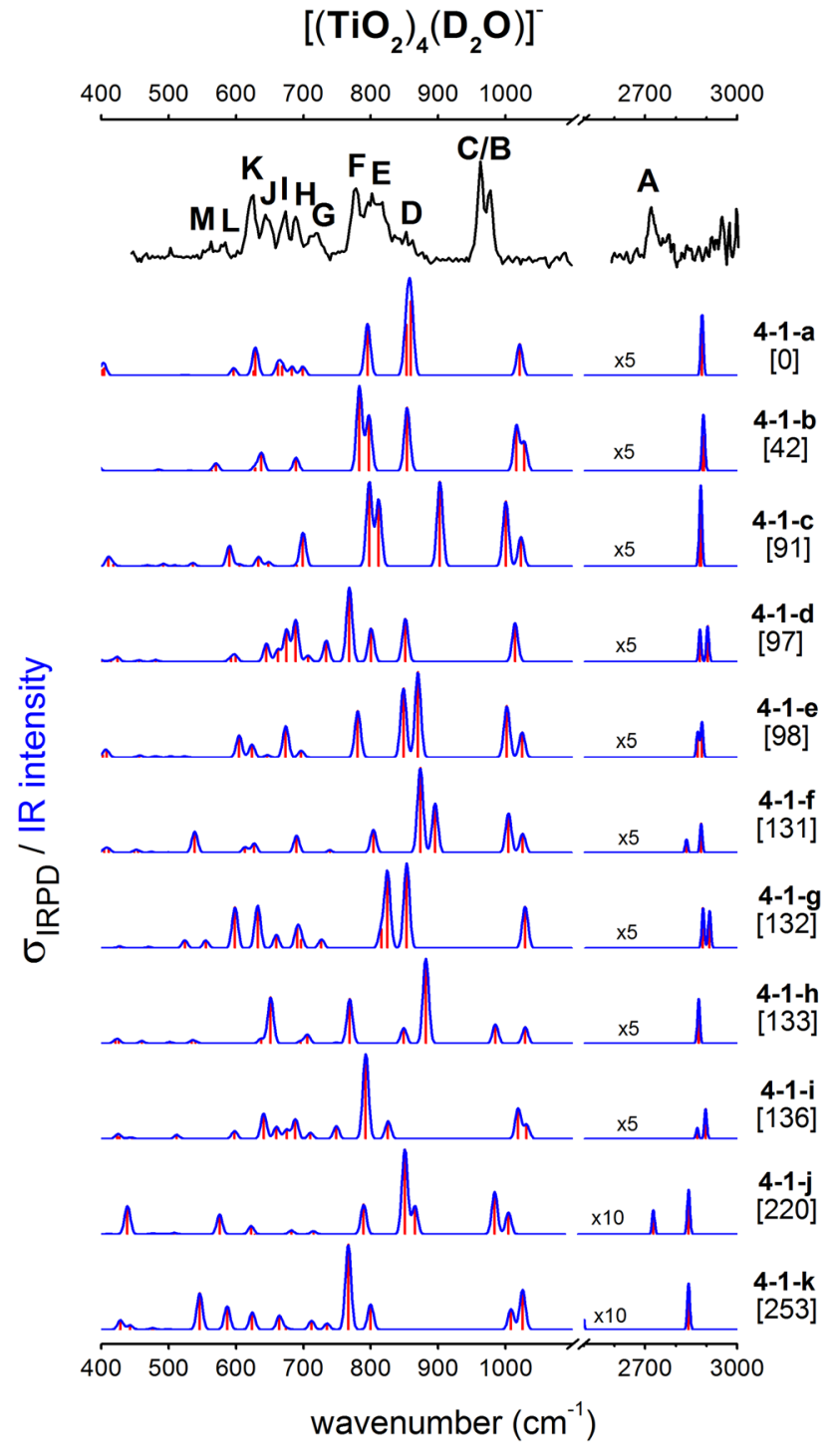

Fig. 6 Experimental IRPD spectra (black) of $\mathrm{D}_{2}$-tagged $\left[\left(\mathrm{TiO}_{2}\right)_{4}\left(\mathrm{D}_{2} \mathrm{O}\right)\right]^{-}$, simulated unscaled linear IR absorption spectra plotted with sticks (red) and a $10 \mathrm{~cm}^{-1}$ fwhm Gaussian convolution (blue), and relative energies $(\mathrm{kJ} / \mathrm{mol})$ of the predicted lowest-lying isomers at the $\omega \mathrm{B} 97 \mathrm{X}-\mathrm{D} / \mathrm{aVDZ}$ level of theory

than 2-1-a, and corresponds to the global minimum-energy structure reported for the neutral cluster [51, 63]. The second water molecule is also predicted to adsorb dissociatively, forming the $C_{1}$-symmetry $\mathbf{2 - 2}$-a structure, with two terminal O-D groups on each now four-fold coordinated $\mathrm{Ti}$ atom. In 2-2-a, the unpaired electron is localized on one $\mathrm{Ti}$ atom and the two bridging $\mathrm{O}$ atoms are shifted towards the other Ti atom. Structures with $\mathbf{2 - 2 - a}$ connectivity but higher symmetry are also predicted to be lowest in energy for the neutral system [50, 51, 54, 55, 61, 63]; Dixon and coworkers [63] report a $C_{2 v}$ structure for the corresponding neutral cluster only slightly distorted from $D_{2 d}$ symmetry.

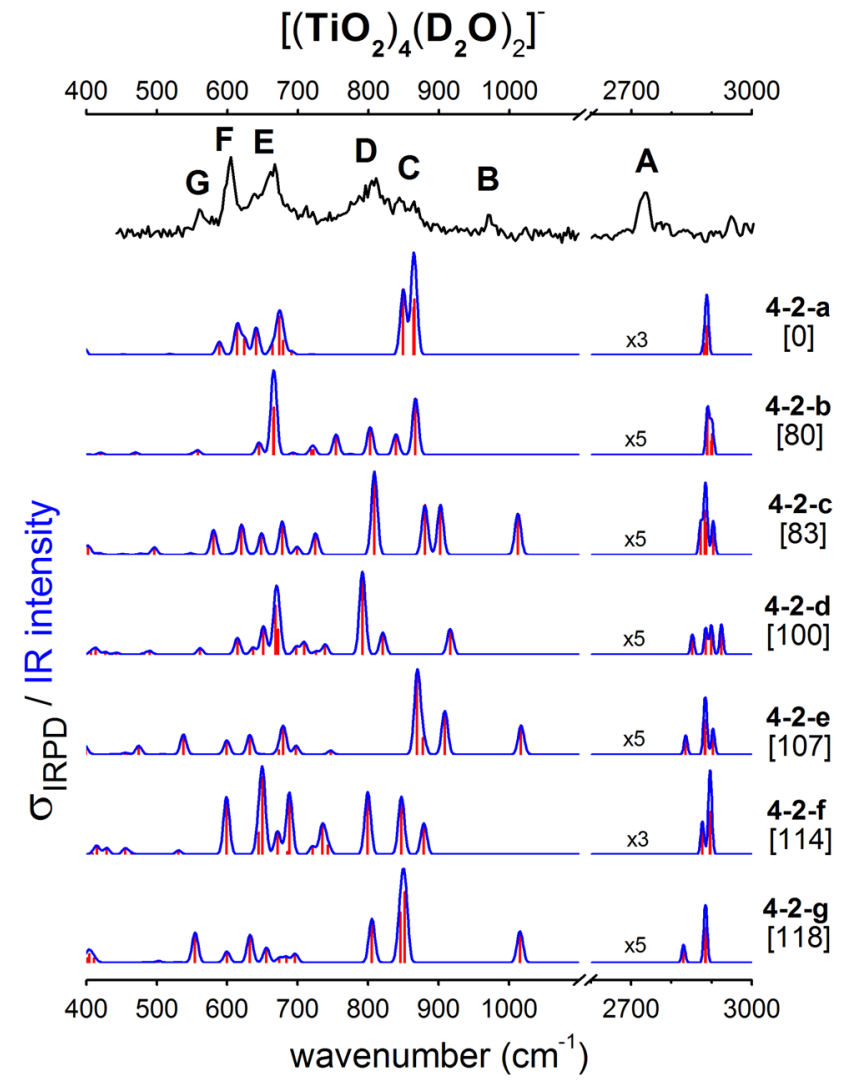

Fig. 7 Experimental IRPD spectra (black) of $\mathrm{D}_{2}$-tagged $\left[\left(\mathrm{TiO}_{2}\right)_{4}\left(\mathrm{D}_{2} \mathrm{O}\right)_{2}\right]^{-}$, simulated unscaled linear IR absorption spectra plotted with sticks (red) and a $10 \mathrm{~cm}^{-1}$ fwhm Gaussian convolution (blue), and relative energies $(\mathrm{kJ} / \mathrm{mol})$ of the predicted lowest-lying isomers at the $\omega \mathrm{B} 97 \mathrm{X}-\mathrm{D} / \mathrm{aVDZ}$ level of theory

Table 1 Experimental vibrational frequencies $\left(\mathrm{cm}^{-1}\right)$ from the IRPD spectra of $\mathrm{D}_{2}$-tagged $\left[\left(\mathrm{TiO}_{2}\right)_{2}\left(\mathrm{D}_{2} \mathrm{O}\right)_{m}\right]^{-}$clusters and the corresponding $\omega \mathrm{B} 97 \mathrm{X}-\mathrm{D} / \mathrm{aVDZ}$ calculated frequencies of the global minimum structures 2-1-a and 2-2-a

\begin{tabular}{|c|c|c|c|c|c|}
\hline \multicolumn{3}{|c|}{$\left[\left(\mathrm{TiO}_{2}\right)_{2}\left(\mathrm{D}_{2} \mathrm{O}\right)\right]^{-}$} & \multicolumn{3}{|c|}{$\left[\left(\mathrm{TiO}_{2}\right)_{2}\left(\mathrm{D}_{2} \mathrm{O}\right)_{2}\right]^{-}$} \\
\hline Band & Expt. & $\begin{array}{l}\omega \mathrm{B} 97 \mathrm{X}-\mathrm{D} \\
\mathbf{2 - 1 - a}\end{array}$ & Band & Expt. & $\begin{array}{l}\omega \mathrm{B} 97 \mathrm{X}-\mathrm{D} \\
\mathbf{2 - 2 - \mathbf { a }}\end{array}$ \\
\hline $\mathbf{A}$ & $2776(25)$ & 2930 & $\mathbf{A}$ & $2732(23)$ & 2894 \\
\hline $\mathbf{B}$ & $2709(23)$ & 2882 & & & 2893 \\
\hline $\mathbf{C}$ & $951(9)$ & 996 & & & 2893 \\
\hline D & $781(13)$ & 783 & & & 2892 \\
\hline $\mathbf{E}$ & $723(10)$ & 728 & B & $740(27)$ & 740 \\
\hline $\mathbf{F}$ & $652(10)$ & 653 & $\mathbf{C}$ & $669(14)$ & 677 \\
\hline $\mathbf{G}$ & $629(9)$ & 629 & D & $650(9)$ & 653 \\
\hline $\mathbf{H}$ & $584(10)$ & 589 & $\mathbf{E}$ & $590(20)$ & 602 \\
\hline * & $2900(33)$ & & $*$ & 2929 (33) & \\
\hline
\end{tabular}

Band positions and full widths at half-maximum (in parentheses) are determined by a least squares fit of a Gaussian line function to the experimental data

$* D_{2}$ stretching features 
Table 2 Experimental vibrational frequencies $\left(\mathrm{cm}^{-1}\right)$ from the IRPD spectra of $\mathrm{D}_{2}$-tagged $\left[\left(\mathrm{TiO}_{2}\right)_{3}\left(\mathrm{D}_{2} \mathrm{O}\right)_{m}\right]^{-}$clusters and the corresponding $\omega \mathrm{B} 97 \mathrm{X}-\mathrm{D} / \mathrm{aVDZ}$ calculated frequencies of the global minimum structures 3-1-a, 3-2-a, and 3-3-a

\begin{tabular}{|c|c|c|c|c|c|c|c|c|}
\hline \multicolumn{3}{|c|}{$\left[\left(\mathrm{TiO}_{2}\right)_{3}\left(\mathrm{D}_{2} \mathrm{O}\right)\right]^{-}$} & \multicolumn{3}{|c|}{$\left[\left(\mathrm{TiO}_{2}\right)_{3}\left(\mathrm{D}_{2} \mathrm{O}\right)_{2}\right]^{-}$} & \multicolumn{3}{|c|}{$\left[\left(\mathrm{TiO}_{2}\right)_{3}\left(\mathrm{D}_{2} \mathrm{O}\right)_{3}\right]^{-}$} \\
\hline Band & Expt. & $\omega$ B97X-D 3-1-a & Band & Expt. & $\omega \mathrm{B} 97 \mathrm{X}-\mathrm{D}$ 3-2-a & Band & Expt. & $\omega$ B97X-D 3-3-a \\
\hline $\mathbf{A}$ & $2761(34)$ & 2920 & $\mathbf{A}$ & $2746(31)$ & 2906 & $\mathbf{A}$ & 2719 (17) & 2888 \\
\hline B & $2728(20)$ & 2890 & & & 2901 & & & 2883 \\
\hline $\mathbf{C}$ & $955(11)$ & 1002 & B & 2719 (17) & 2883 & & & 2881 \\
\hline D & 784 (13) & 819 & C & $2639(38)$ & 2807 & & & 2879 \\
\hline $\mathbf{E}$ & $748(21)$ & 768 & D & $792(19)$ & 835 & & & 2875 \\
\hline $\mathbf{F}$ & $696(16)$ & 709 & $\mathbf{E}$ & $771(12)$ & 800 & & & 2865 \\
\hline $\mathbf{G}$ & 659 (14) & 672 & $\mathbf{F}$ & $738(9)$ & 746 & $\mathbf{B}$ & 855 (17) & 902 \\
\hline \multirow[t]{3}{*}{$\mathbf{H}$} & $635(20)$ & 655 & $\mathbf{G}$ & $692(9)$ & 704 & $\mathbf{C}$ & $844(10)$ & 885 \\
\hline & & 641 & & & 695 & D & $700(23)$ & 719 \\
\hline & & 633 & & & 685 & $\mathbf{E}$ & $694(5)$ & 702 \\
\hline $\mathbf{I}$ & $571(11)$ & 584 & $\mathbf{H}$ & $645(10)$ & 654 & & & 688 \\
\hline \multirow[t]{6}{*}{$*$} & $2920(22)$ & & $\mathbf{I}$ & $626(10)$ & 643 & & & 684 \\
\hline & & & $\mathbf{J}$ & $586(14)$ & 601 & $\mathbf{F}$ & $664(5)$ & 651 \\
\hline & & & $\mathbf{K}$ & $561(14)$ & 582 & G & 627 (16) & 635 \\
\hline & & & $*$ & $2928(38)$ & & $\mathbf{H}$ & $606(15)$ & 597 \\
\hline & & & & & & I & 564 (18) & 569 \\
\hline & & & & & & $\mathbf{J}$ & $546(11)$ & \\
\hline
\end{tabular}

Band positions and full widths at half-maximum (in parentheses) are determined by a least squares fit of a Gaussian line function to the experimental data

$* \mathrm{D}_{2}$ stretching features

Table 3 Experimental vibrational frequencies $\left(\mathrm{cm}^{-1}\right)$ from the IRPD spectra of $\mathrm{D}_{2}$-tagged $\left[\left(\mathrm{TiO}_{2}\right)_{4}\left(\mathrm{D}_{2} \mathrm{O}\right)_{m}\right]^{-}$ clusters and the corresponding $\omega \mathrm{B} 97 \mathrm{X}-\mathrm{D} / \mathrm{aVDZ}$ calculated frequencies of the low-energy structures 4-1-a, 4-1-b, 4-2-a, and 4-2-c

\begin{tabular}{|c|c|c|c|c|c|c|c|}
\hline \multicolumn{4}{|c|}{$\left[\left(\mathrm{TiO}_{2}\right)_{4}\left(\mathrm{D}_{2} \mathrm{O}\right)\right]^{-}$} & \multicolumn{4}{|c|}{$\left[\left(\mathrm{TiO}_{2}\right)_{4}\left(\mathrm{D}_{2} \mathrm{O}\right)_{2}\right]^{-}$} \\
\hline \multirow[t]{2}{*}{ Band } & \multirow[t]{2}{*}{ Expt. } & \multicolumn{2}{|c|}{$\omega \mathrm{B} 97 \mathrm{X}-\mathrm{D}$} & \multirow[t]{2}{*}{ Band } & \multirow[t]{2}{*}{ Expt. } & \multicolumn{2}{|c|}{$\omega \mathrm{B} 97 \mathrm{X}-\mathrm{D}$} \\
\hline & & 4-1-a & 4-1-b & & & 4-2-a & 4-2-c \\
\hline \multirow[t]{2}{*}{$\mathbf{A}$} & $2723(30)$ & 2885 & 2892 & $\mathbf{A}$ & 2732 (29) & 2889 & 2904 \\
\hline & & 2885 & 2888 & & & 2888 & 2886 \\
\hline B & 977 (11) & 1021 & 1028 & & & 2888 & 2883 \\
\hline $\mathbf{C}$ & $963(10)$ & & 1016 & & & 2881 & 2873 \\
\hline D & $853(21)$ & 859 & 854 & B & $972(9)$ & & 1012 \\
\hline $\mathbf{E}$ & $805(42)$ & 853 & 797 & $\mathbf{C}$ & 849 (93) & 865 & 902 \\
\hline $\mathbf{F}$ & $776(12)$ & 795 & 783 & & & 864 & 880 \\
\hline G & $716(23)$ & 699 & & D & $806(36)$ & 850 & 809 \\
\hline $\mathbf{H}$ & $689(11)$ & 683 & 689 & $\mathbf{E}$ & $663(20)$ & 679 & 725 \\
\hline I & $672(13)$ & 669 & & & & 673 & 699 \\
\hline $\mathbf{J}$ & $646(17)$ & 662 & 638 & & & 664 & 678 \\
\hline \multirow[t]{2}{*}{$\mathbf{K}$} & $623(14)$ & 629 & 629 & & & & 648 \\
\hline & & 626 & 628 & $\mathbf{F}$ & $604(15)$ & 641 & 620 \\
\hline $\mathbf{L}$ & $582(11)$ & 597 & & & & 624 & \\
\hline \multirow[t]{3}{*}{ M } & $562(17)$ & & 571 & & & 614 & \\
\hline & & & & G & $562(13)$ & 588 & 580 \\
\hline & & & & * & $2950(20)$ & & \\
\hline
\end{tabular}

Band positions and full widths at half-maximum (in parentheses) are determined by a least squares fit of a Gaussian line function to the experimental data

$* \mathrm{D}_{2}$ stretching features 
We assign the experimental $\left[\left(\mathrm{TiO}_{2}\right)_{2}\left(\mathrm{D}_{2} \mathrm{O}\right)_{m}\right]^{-}$vibrational features through comparison with the simulated IR spectra (Fig. 4; Table 1). The agreement between the harmonic spectrum of the lowest-energy structure 2-1-a and the IRPD spectrum of $\left[\left(\mathrm{TiO}_{2}\right)_{2}\left(\mathrm{D}_{2} \mathrm{O}\right)\right]^{-}$is reasonable, and better than that for the three higher-lying isomers. Inclusion of a physisorbed $\mathrm{D}_{2}$ tag in the 2-1-a calculation produces nearly identical results and confirms that the tag is non-perturbing (Fig. S3). All experimental features are reproduced, though there are deviations in the band positions and relative intensities. Such deviations are observed throughout Figs. 4, 5, 6 and 7 and we attribute them to the limitations of the DFT functional used as well as anharmonic effects. Of the two O-D stretching modes in region (i), the higher-frequency mode (peak A) corresponds to motion of the hydroxyl group on the undercoordinated $\mathrm{Ti}$ atom, while the single terminal Ti-O group gives rise to peak $\mathrm{C}$ in region (ii). Peaks $\mathrm{D}$ and $\mathrm{E}$ in region (iii) correspond, respectively, to symmetric and antisymmetric stretching modes of the two Ti-O-Ti bridges, while peaks $\mathrm{F}, \mathrm{G}$, and $\mathrm{H}$ correspond to Ti-O-D bending modes.

For $\left[\left(\mathrm{TiO}_{2}\right)_{2}\left(\mathrm{D}_{2} \mathrm{O}\right)_{2}\right]^{-}$, the spectrum of $\mathbf{2 - 2}$-a is a better match for the experimental IRPD spectrum than 2-2b or 2-2-c, as it reproduces the main spectral features, in particular the lack of any absorption in region (ii). We observe a single sharp feature (peak A) in region (i), reproduced by four nearly degenerate 2-2-a O-D stretching modes. In region (iv), peaks $\mathrm{C}, \mathrm{D}$, and $\mathrm{E}$ are closely reproduced by DFT and correspond to Ti-O-D stretching and bending modes. However, in region (iii), where the spectrum of $\mathbf{2 - 2 - a}$ shows two distinct Ti-O-Ti bridge stretching features at 804 (symmetric stretch) and $740 \mathrm{~cm}^{-1}$ (antisymmetric stretch), the experimental spectrum shows only a single broad feature (peak B) centered at $740 \mathrm{~cm}^{-1}$.

This discrepancy results from significant anharmonicity of the $804 \mathrm{~cm}^{-1} \mathrm{Ti}-\mathrm{O}-\mathrm{Ti}$ bridge stretching mode of 2-2a. This mode exhibits a double-well vibrational potential, similar to that described for $\mathrm{V}_{6} \mathrm{O}_{15}{ }^{-}$and $\mathrm{V}_{8} \mathrm{O}_{20}{ }^{-}$[82], that connects two equivalent $C_{1}$-symmetric local minima via a $C_{2}$-symmetric transition state (TS) structure lying $25 \mathrm{~kJ} /$ mol $\left(2100 \mathrm{~cm}^{-1}\right)$ higher. The vibrational displacement vectors of the mode with imaginary frequency at the $C_{2}$ geometry are shown in Fig. S4a. This barrier causes inversion splitting of each vibrational level and leads to a significant red shift of the IR absorption relative to the harmonic frequency calculated at the minimum-energy geometry. This likely results in an experimental vibrational feature that contributes to the broad experimental peak B. Fig. $\mathrm{S} 4 \mathrm{~b}$ compares the simulated harmonic IR spectrum at the 2-2-a TS geometry to that of the 2-2-a minima and the experimental IRPD spectrum.

\section{$4.2\left[\left(\mathrm{TiO}_{2}\right)_{3}\left(\mathrm{D}_{2} \mathrm{O}\right)_{m}\right]^{-}$}

The IRPD spectrum of $\mathrm{D}_{2}$-tagged $\left[\left(\mathrm{TiO}_{2}\right)_{3}\left(\mathrm{D}_{2} \mathrm{O}\right)\right]^{-}$shows two closely spaced $\mathrm{O}-\mathrm{D}$ features in region (i), one strong $\mathrm{Ti}-\mathrm{O}$ feature in region (ii), and intense features in region (iii) continuing into region (iv) (Fig. 1). With the addition of a second water molecule in $\left[\left(\mathrm{TiO}_{2}\right)_{3}\left(\mathrm{D}_{2} \mathrm{O}\right)_{2}\right]^{-}$and a third in $\left[\left(\mathrm{TiO}_{2}\right)_{3}\left(\mathrm{D}_{2} \mathrm{O}\right)_{3}\right]^{-}$, the IRPD spectra show the structure in region (i) merging into a single feature, a complete absence of features in region (ii), and intense structure in regions (iii) and (iv) blue-shifting with additional water molecules.

The comparison between experimental and calculated vibrational structure is reasonably straightforward for all three $\left[\left(\mathrm{TiO}_{2}\right)_{3}\left(\mathrm{D}_{2} \mathrm{O}\right)_{m}\right]^{-}$structures (Fig. 5; Table 2). In previous work, we assigned the lowest-energy isomer of the bare $\left(\mathrm{TiO}_{2}\right)_{3}{ }^{-}$cluster to the 3-0-a structure (Fig. 2) [13]. For $\left[\left(\mathrm{TiO}_{2}\right)_{3}\left(\mathrm{D}_{2} \mathrm{O}\right)\right]^{-}$, the lowest-energy structure 3-1-a corresponds to dissociative adsorption of $\mathrm{D}_{2} \mathrm{O}$ on $\mathbf{3 - 0 - a}$, with two terminal O-D groups on neighboring Ti atoms and one remaining terminal $\mathrm{Ti}-\mathrm{O}$ group (Fig. 3). This structure has also been predicted to be the global minimum for the corresponding neutral cluster [53,63].

The simulated IR spectrum of 3-1-a reproduces all experimental vibrational features reasonably well. The two O-D stretching modes in region (i) are predicted, as is the sole terminal Ti-O stretching mode in region (ii). The two strong peaks $\mathrm{D}$ and $\mathrm{E}$ in region (iii) correspond to $\mathrm{Ti}-\mathrm{O}-\mathrm{Ti}$ bridge stretches, while weaker peaks $\mathrm{F}$ and $\mathrm{G}$ in region (iv) correspond to Ti-O-Ti bridge stretches and Ti-O-D stretches, respectively. The modes underlying experimental peak $\mathrm{H}$ correspond to delocalized stretching modes involving the $\mathrm{Ti}-\mathrm{O}-\mathrm{Ti}$ bridges, Ti-O-D moieties, and the central triply coordinated $\mathrm{O}$ atom.

The $\left[\left(\mathrm{TiO}_{2}\right)_{3}\left(\mathrm{D}_{2} \mathrm{O}\right)_{2}\right]^{-}$global minimum-energy structure 3-2-a (Fig. 3) follows directly from addition of a second $\mathrm{D}_{2} \mathrm{O}$ on 3-1-a, forming two terminal O-D groups at the previous site of the terminal Ti-O group, and releasing the strain of the central triply coordinated $\mathrm{O}$ atom. As was also the case for 3-1-a, the 3-2-a structure is the lowest-energy structure of the corresponding neutral cluster [54,63]. Interpretation of the $\left[\left(\mathrm{TiO}_{2}\right)_{3}\left(\mathrm{D}_{2} \mathrm{O}\right)_{2}\right]^{-}$spectrum proceeds through reasonable agreement with the 3-2-a spectrum. In region (i), peak A encompasses stretching motion of the two O-D moieties on separate Ti atoms, while the lower frequency peaks B and $\mathrm{C}$ correspond to stretching of each of the two O-D groups that share the remaining $\mathrm{Ti}$ atom. In region (iii), overlapping experimental peaks $\mathrm{D}$ and $\mathrm{E}$ correspond to Ti-O-Ti bridge stretching modes, as does the weak peak $\mathrm{F}$ in region (iv). A cluster of delocalized ring stretching modes underlie peak $\mathrm{G}$, while intense peaks $\mathrm{H}$ and I correspond to stretching of the Ti-O-D moieties that do not share a Ti atom. Weak features $\mathrm{J}$ and $\mathrm{K}$ involve Ti-O-Ti bridge stretching and Ti-O-D bending and stretching modes. 
The minimum-energy structure of $\left[\left(\mathrm{TiO}_{2}\right)_{3}\left(\mathrm{D}_{2} \mathrm{O}\right)_{3}\right]^{-}$, 3-3-a, is formed through addition of a third $\mathrm{D}_{2} \mathrm{O}$ to 3-2a, and results in two terminal $\mathrm{O}-\mathrm{D}$ groups on each of the three four-fold coordinated Ti centers. The same structure has been widely predicted for neutral $\left[\left(\mathrm{TiO}_{2}\right)_{3}\left(\mathrm{H}_{2} \mathrm{O}\right)_{3}\right]$ $[53,54,63]$. The assignment of the IRPD spectrum of $\left[\left(\mathrm{TiO}_{2}\right)_{3}\left(\mathrm{D}_{2} \mathrm{O}\right)_{3}\right]^{-}$to that of $\mathbf{3 - 3 - a}$ is quite clear, as the simulated spectra of higher-lying candidates lack the characteristic gap in structure between 700 and $800 \mathrm{~cm}^{-1}$. Additionally, only the spectrum of 3-3-a has a single sharp feature in region (i), due to the six quasi-equivalent terminal O-D groups. The overlapping peaks $\mathrm{B} / \mathrm{C}$ near the high energy edge of region (iii) are attributed to the coordinated motion of all three quasi-equivalent $\mathrm{Ti}-\mathrm{O}-\mathrm{Ti}$ bridges. In region (iv), peaks D/E correspond to calculated Ti-O-D modes, while peaks F, G, H, and I correspond to coupled Ti-O-D stretching and ring breathing as well as a delocalized bridge stretching mode.

\section{$4.3\left[\left(\mathrm{TiO}_{2}\right)_{4}\left(\mathrm{D}_{2} \mathrm{O}\right)_{m}\right]^{-}$}

The IRPD spectrum of $\mathrm{D}_{2}$-tagged $\left[\left(\mathrm{TiO}_{2}\right)_{4}\left(\mathrm{D}_{2} \mathrm{O}\right)\right]^{-}$shows a single $\mathrm{O}-\mathrm{D}$ stretching feature in region (i), two strong $\mathrm{Ti}-\mathrm{O}$ stretching features in region (ii), broad structure spanning region (iii), and several weaker features in region (iv) (Fig. 1). With the addition of the second water, the IRPD spectrum for $m=2$ shows one $\mathrm{O}-\mathrm{D}$ feature in region (i), a single weak $\mathrm{Ti}-\mathrm{O}$ feature in region (ii), further unresolved structure spanning region (iii), and more intense, broad structure in region (iv). The persistent $\mathrm{Ti}-\mathrm{O}$ features in region (ii) of these IRPD spectra represent a departure from the spectra of the $n=2,3$ clusters, where complete loss of $\mathrm{Ti}-\mathrm{O}$ structure with increasing addition of water was a clear indicator of dissociative adsorption. The analogous $\mathrm{D}_{2} \mathrm{O}$-loss IRMPD spectra shown in Fig. S2 are also quite distinct from the IRPD spectra for both $n=4$ clusters.

The $\left[\left(\mathrm{TiO}_{2}\right)_{4}\left(\mathrm{D}_{2} \mathrm{O}\right)_{m}\right]^{-}$IRPD spectra are compared to harmonic IR spectra of low-lying isomers in Figs. 6 and 7, with frequencies listed in Table 3. For $\left[\left(\mathrm{TiO}_{2}\right)_{4}\left(\mathrm{D}_{2} \mathrm{O}\right)\right]^{-}$, the predicted lowest-energy structure 4-1-a (Fig. 3) is similar to that found for $\left[\left(\mathrm{TiO}_{2}\right)_{4}\left(\mathrm{H}_{2} \mathrm{O}\right)\right][53,63]$. However, the IRPD spectrum distinctly shows two Ti-O stretching features in region (ii), while the spectrum of 4-1-a exhibits only one, due to the presence of only a single Ti-O moiety. A contribution from 4-1-b, the next lowest-lying isomer at $42 \mathrm{~kJ} / \mathrm{mol}$ above 4-1-a, could account for the extra terminal Ti-O stretching spectral feature. 4-1-b has the same core cluster structure as 4-1-a, but with one terminal and one bridging O-D group; similar clusters have been considered in the literature as hydrolysis intermediates [53, 61]. It is also possible that the bridging O-D structure 4-1-c contributes. Though 4-1-c lies even higher in energy, at $91 \mathrm{~kJ} / \mathrm{mol}$ above 4-1-a, it represents an intermediate structure on the pathway to form 4-1-a after initial molecular adsorption of $\mathrm{D}_{2} \mathrm{O}$ on $\left(\mathrm{TiO}_{2}\right)_{4}{ }^{-}$and transfer of one D atom [53, 61]. 4-1-c could therefore be populated due to kinetic trapping as the result of a high barrier for the second $\mathrm{D}$ atom transfer step required to form 4-1-a.

Experimentally, we observe one region (i) feature. This is consistent with the potential presence of both 4-1-a and 4-1b clusters, which have close-lying O-D stretching modes. In region (ii), 4-1-b has two Ti-O stretching frequencies derived from its two remaining terminal $\mathrm{Ti}-\mathrm{O}$ moieties which straddle the single 4-1-a Ti-O stretching frequency. These three overlapping features could explain the experimental peaks $\mathrm{B}$ and $\mathrm{C}$ in region (ii). The broad experimental structure in region (iii) can be ascribed to overlapping 4-1-a and 4-1-b features corresponding to stretching modes involving all four nearly equivalent $\mathrm{Ti}-\mathrm{O}-\mathrm{Ti}$ bridges.

For $\left[\left(\mathrm{TiO}_{2}\right)_{4}\left(\mathrm{D}_{2} \mathrm{O}\right)_{2}\right]^{-}, \mathbf{4 - 2 - a}$ is by far the lowest-energy structure, just as in the neutral cluster [63]. The corresponding IRPD spectrum shows one $\mathrm{Ti}-\mathrm{O}$ feature in region (ii), indicating at least some dissociative adsorption of $\mathrm{D}_{2} \mathrm{O}$ after the addition of a second water. However, the lowest-lying 4-2-a structure has no remaining $\mathrm{Ti}-\mathrm{O}$ moieties and thus no features in region (ii). Structure 4-2-c, which is calculated to lie $83 \mathrm{~kJ} / \mathrm{mol}$ above $\mathbf{4 - 2}$-a, is the lowest-lying structure with a bridging $\mathrm{O}-\mathrm{D}$ group, and reproduces the Ti-O stretching peak. Between structures 4-2-a and 4-2-c, the IRPD spectrum for $m=2$ can largely be explained. In region (i), we observe a single experimental feature which is consistent with the nearly iso-energetic O-D stretching modes of 4-2a and 4-2-c. Peak B in region (ii) corresponds to the Ti-O stretching feature in 4-2-c. In region (iii), Ti-O-Ti bridge stretching peaks at from both 4-2-a and 4-2-c could underlie the broad experimental structure. Similar to the situation for $m=1$, kinetic trapping of higher energy isomers may not be negligible following water adsorption and formation of $\left[\left(\mathrm{TiO}_{2}\right)_{4}\left(\mathrm{D}_{2} \mathrm{O}\right)_{2}\right]^{-}$.

Ultimately, while we are unable to make definitive spectral and structural assignments for the $\left[\left(\mathrm{TiO}_{2}\right)_{4}\left(\mathrm{D}_{2} \mathrm{O}\right)_{m}\right]^{-}$clusters, it is reasonable to ascribe the observed structure to contributions from several isomers. Experimentally, the presence of structures with bridging $\mathrm{O}-\mathrm{D}$ groups suggests that there may be significant isomerization barriers to form the lowestenergy $n=4$ clusters, leading to kinetic trapping of reactive intermediates. Similar kinetic trapping has also been discussed in a study of hydrolysis on group VI transition metal oxide cluster anions [37].

\subsection{Structural Trends}

The agreement between the simulated IR spectrum for the global minimum-energy structure and the corresponding IRPD spectrum is reasonable for each cluster considered here, though higher-energy isomers must also contribute to the $n=4$ IRPD spectra. We confirm that the theoretical 
predictions made by Dixon and coworkers [63] for the neutral $\left[\left(\mathrm{TiO}_{2}\right)_{n}\left(\mathrm{H}_{2} \mathrm{O}\right)_{m}\right]$ clusters hold for their deuterated anionic analogs: dissociative adsorption proceeds spontaneously on $\left(\mathrm{TiO}_{2}\right)_{n}{ }^{-}$for the first two water molecules with $n=2$ and for the first three water molecules with $n=3$. Our DFT calculations for all $n=2-4$ anions reproduce the same minimum-energy structures that Dixon and coworkers found for the neutral clusters [63], with the exception of $\left[\left(\mathrm{TiO}_{2}\right)_{2}\left(\mathrm{D}_{2} \mathrm{O}\right)\right]^{-}$. Taken together, these results indicate that the excess electron present in the $\left(\mathrm{TiO}_{2}\right)_{n}{ }^{-}$clusters does not drastically affect the structural aspects of water dissociation. On the other hand, the energetics of water dissociation on $\left(\mathrm{TiO}_{2}\right)_{n}{ }^{-}$are likely to depend on the presence of an excess charge. Comparing the water-splitting reaction energy landscapes of $\left(\mathrm{TiO}_{2}\right)_{6}{ }^{0 /+/-}$, Du et al. [53] found that the barrier for initial dissociation of molecularly adsorbed water was lowest in the anion, but that the three charge states had similar barriers for the subsequent $\mathrm{H}$ atom transfer to form the global minimum energy structures containing terminal hydroxyl groups.

Using the $\left[\left(\mathrm{TiO}_{2}\right)_{n}\left(\mathrm{D}_{2} \mathrm{O}\right)_{m}\right]^{-}$minimum-energy structures, we can consider the size-dependent evolution of their geometries, vibrational structure, and reactivity. For all cluster anions considered here, dissociative adsorption proceeds preferentially at the undercoordinated $\mathrm{Ti}$ sites, and continues with the addition of subsequent water molecules until all Ti sites have coordination numbers of four, and all terminal Ti-O moieties have been hydroxylated. The hydrolysis limit of each bare $\left(\mathrm{TiO}_{2}\right)_{n}{ }^{-}$cluster is therefore closely related to the initial number of unsaturated $\mathrm{Ti}$ atoms. The $\left(\mathrm{TiO}_{2}\right)_{3}{ }^{-}$cluster is a special case, as the 3-0-a structure has one coordinatively unsaturated $\mathrm{Ti}$ atom and a triply coordinated central $\mathrm{O}$ atom. All Ti atoms in this cluster are already fourfold coordinated after reaction with one water to form 3-1-a, but it remains favorable for the cluster to go on to dissociatively adsorb a second and third water molecule in order to reduce the strain of the central $\mathrm{O}$ atom in 3-1-a and the two Ti-O-Ti bridges that share Ti atoms in 3-2-a [63].

Site-specific reactivity is also closely related to the localization of the singly occupied molecular orbital (SOMO) of the doublet electronic ground state for each anion. Li and Dixon report the SOMOs for the bare $\left(\mathrm{TiO}_{2}\right)_{n}{ }^{-}$clusters with $n=2-4$ [78], while we plot the SOMOs for relevant $\left[\left(\mathrm{TiO}_{2}\right)_{n}\left(\mathrm{D}_{2} \mathrm{O}\right)_{m}\right]^{-}$isomers in Fig. $\mathrm{S} 5$. In the bare clusters, the SOMO is always localized on the undercoordinated $\mathrm{Ti}$ atoms. In all cases, reaction with the first $\mathrm{D}_{2} \mathrm{O}$ adds a dangling Ti-O moiety to one of these undercoordinated reactive sites, increasing its coordination number to four. 2-1-a, 4-1-a, and 4-1-b have SOMOs localized to the last remaining undercoordinated Ti atom, while the 3-1-a SOMO is more delocalized as all $\mathrm{Ti}$ atoms are already fully coordinated. The SOMOs grow more delocalized with the addition of subsequent water molecules. This is in good agreement with bulk titania surface studies, which find that dissociative water adsorption occurs preferentially at defect sites, and particularly at oxygen vacancies on undercoordinated $\mathrm{Ti}$ atoms [25]. This finding reiterates the validity of these small clusters as models for reactive point defects.

The trends in vibrational frequencies and intensities observed as a function of cluster size and increasing water adsorption are also of interest; the spectral signatures of water adsorption described here may inform spectroscopic studies of water dissociation and oxidation intermediates on bulk $\mathrm{TiO}_{2}$ surfaces [83-88]. The clearest indicator of dissociative water adsorption is the disappearance of structure in the Ti-O stretching regime from 900 to $1000 \mathrm{~cm}^{-1}$, as terminal $\mathrm{Ti}-\mathrm{O}$ moieties react to form $\mathrm{Ti}-\mathrm{O}-\mathrm{D}$ groups with sequential addition of $\mathrm{D}_{2} \mathrm{O}$. These Ti-O-D groups have low-frequency stretching, bending, and wagging vibrational modes, leading to increased intense structure below $700 \mathrm{~cm}^{-1}$ in region (iv) with the addition of water. The separation between features in the O-D stretching region $(i)$ decreases with increasing water adsorption, while structure in the $\mathrm{Ti}-\mathrm{O}-\mathrm{Ti}$ bridge stretching region (iii) tends to blue-shift with increasing water adsorption.

Our IRPD results are consistent with prior vibrational studies of hydrated bulk $\mathrm{TiO}_{2}$. Spectral assignments associated with dissociative water adsorption on $\mathrm{TiO}_{2}$ surfaces in the literature have largely been based on $\mathrm{O}-\mathrm{H}$ stretching frequencies. Many groups assign vibrational structure in the $3650-3750 \mathrm{~cm}^{-1}$ window to surface-bound hydroxyl groups [19, 83-87]. Finnie et al. [85] reported two distinct $\mathrm{O}-\mathrm{H}$ vibrational features at 3730 and $3670 \mathrm{~cm}^{-1}$ that remained on a $\mathrm{TiO}_{2}$ film after dehydration at high temperatures and assigned them to terminal and bridging O-H group stretches, respectively. Henderson [19], on the other hand, studied the vibrational features of a hydrated $\mathrm{TiO}_{2}$ surface with electron energy loss spectroscopy and saw only one feature in this region at $3690 \mathrm{~cm}^{-1}$. In this work, we report $\mathrm{O}-\mathrm{D}$ stretches in a fairly narrow $2709-2776 \mathrm{~cm}^{-1}$ range, which can be scaled by a factor of $1.36[40,89]$ to yield comparable $\mathrm{O}-\mathrm{H}$ stretching frequencies in the $3684-3775 \mathrm{~cm}^{-1}$ range, in good agreement with the bulk surface assignments. In contrast to the previous study of water adsorption on $\mathrm{Al}_{3} \mathrm{O}_{4}{ }^{+}$[40], we see no major distinction in stretching frequencies between terminal and bridging hydroxyl groups; compare, for instance, the harmonic IR spectra of structures 4-1-a and 4-1-b in Fig. 6. Rather, we find that hydroxyl stretching frequencies are affected by the extent to which they couple to other modes as well as the coordination numbers of neighboring $\mathrm{Ti}$ atoms. More bulk spectroscopic work is needed to fully characterize the vibrational signatures of surface hydroxyl groups in different bonding motifs and environments. 


\section{Summary and Conclusions}

We have reported infrared photodissociation spectra of the cold $\left[\left(\mathrm{TiO}_{2}\right)_{n}\left(\mathrm{D}_{2} \mathrm{O}\right)_{m}\right]^{-}(n=2-4 ; m=1-3)$ clusters messenger-tagged with $\mathrm{D}_{2}$, in the fingerprint $\left(400-1200 \mathrm{~cm}^{-1}\right)$ and O-D stretching $\left(2600-3000 \mathrm{~cm}^{-1}\right)$ ranges. $\omega \mathrm{B} 97 \mathrm{X}-\mathrm{D} / \mathrm{aVDZ}$ calculations allow for structural and spectral assignment of the $n=2,3$ clusters with up to two and three adsorbed waters, respectively. We also comment on the spectra of the $n=4$ clusters, where there appear to be contributions from both the lowest-energy calculated structures and, more speculatively, from reactive intermediates with bridging hydroxyl groups.

We find conclusive evidence that all clusters studied in this work have structures corresponding to dissociative adsorption of the water molecules on the $\left(\mathrm{TiO}_{2}\right)_{n}{ }^{-}$core. The clearest spectral indicator of this process is the disappearance of terminal Ti-O stretching vibrational structure in the $900-1000 \mathrm{~cm}^{-1}$ region that accompanies water adsorption. The $\left[\left(\mathrm{TiO}_{2}\right)_{n}\left(\mathrm{D}_{2} \mathrm{O}\right)_{m}\right]^{-}$clusters studied here are of considerable interest as model systems for photocatalytic water splitting on bulk $\mathrm{TiO}_{2}$. The facile dissociative adsorption of water on undercoordinated $\mathrm{Ti}$ atoms illuminates at the molecular level how hydrolysis reactions may be initiated at reactive $\mathrm{TiO}_{2}$ defect sites.

Acknowledgements This research is funded by the Air Force Office of Scientific Research under Grant No. FA9550-12-1-0160 and by the German Research Foundation (DFG) within the Collaborative Research Center 1109 "Metal Oxide/Water Systems." Calculations were carried out in part using the UC Berkeley College of Chemistry Molecular Graphics and Computation Facility, which is funded by the National Institutes of Health under Grant No. S10OD023532. M.L.W. thanks the National Science Foundation for a graduate research fellowship.

\section{References}

1. Diebold U (2003) The surface science of titanium dioxide. Surf Sci Rep 48:53-229

2. Sato S, White JM (1980) Photoassisted water-gas shift reaction over platinized $\mathrm{TiO}_{2}$ catalysts. J Am Chem Soc 102:7206-7210

3. Henderson MA (2011) A surface science perspective on $\mathrm{TiO}_{2}$ photocatalysis. Surf Sci Rep 66:185-297

4. Habisreutinger SN, Schmidt-Mende L, Stolarczyk JK (2013) Photocatalytic reduction of $\mathrm{CO}_{2}$ on $\mathrm{TiO}_{2}$ and other semiconductors. Angew Chem Int Ed 52:7372-7408

5. O'Regan B, Grätzel M (1991) A low-cost, high-efficiency solar-cell based on dye-sensitized colloidal $\mathrm{TiO}_{2}$ films. Nature 353:737-740

6. Grätzel M (2001) Photoelectrochemical cells. Nature 414:338-344

7. Hoffmann MR, Martin ST, Choi W, Bahnemann DW (1995) Environmental applications of semiconductor photocatalysis. Chem Rev 95:69-96

8. Hashimoto K, Irie H, Fujishima A (2005) $\mathrm{TiO}_{2}$ photocatalysis: a historical overview and future prospects. Jpn J Appl Phys 44:8269-8285
9. Schneider J, Matsuoka M, Takeuchi M, Zhang J, Horiuchi Y, Anpo M, Bahnemann DW (2014) Understanding $\mathrm{TiO}_{2}$ photocatalysis: mechanisms and materials. Chem Rev 114:9919-9986

10. Fujishima A, Honda K (1972) Electrochemical photolysis of water at a semiconductor electrode. Nature 238:37-38

11. Ni M, Leung MKH, Leung DYC, Sumathy K (2007) A review and recent developments in photocatalytic water-splitting using $\mathrm{TiO}_{2}$ for hydrogen production. Renew Sust Energy Rev 11:401-425

12. Tachikawa T, Fujitsuka M, Majima T (2007) Mechanistic insight into the $\mathrm{TiO}_{2}$ photocatalytic reactions: design of new photocatalysts. J Phys Chem C 111:5259-5275

13. Weichman ML, Song X, Fagiani MR, Debnath S, Gewinner S, Schöllkopf W, Neumark DM, Asmis KR (2016) Gas phase vibrational spectroscopy of cold $\left(\mathrm{TiO}_{2}\right)_{n}{ }^{-}(n=3-8)$ clusters. J Chem Phys 144:124308

14. Sun CH, Liu LM, Selloni A, Lu GQ, Smith SC (2010) Titaniawater interactions: a review of theoretical studies. J Mater Chem 20:10319-10334

15. Mu R, Zhao Z-j, Dohnálek Z, Gong J (2017) Structural motifs of water on metal oxide surfaces. Chem Soc Rev 46:1785-1806

16. Diebold U (2017) A controversial benchmark system for wateroxide interfaces: H2O/TiO2(110). J Chem Phys 147(4):040901

17. Kurtz RL, Stockbauer R, Madey TE, Roman E, Desegovia JL (1989) Synchrotron radiation studies of $\mathrm{H}_{2} \mathrm{O}$ adsorption on $\mathrm{TiO}_{2}(110)$. Surf Sci 218:178-200

18. Hugenschmidt MB, Gamble L, Campbell CT (1994) The interaction of $\mathrm{H}_{2} \mathrm{O}$ with a $\mathrm{TiO}_{2}(110)$ surface. Surf Sci 302:329-340

19. Henderson MA (1996) An HREELS and TPD study of water on $\mathrm{TiO}_{2}(110)$ : the extent of molecular versus dissociative adsorption. Surf Sci 355:151-166

20. Brinkley D, Dietrich M, Engel T, Farrall P, Gantner G, Schafer A, Szuchmacher A (1998) A modulated molecular beam study of the extent of $\mathrm{H}_{2} \mathrm{O}$ dissociation on $\mathrm{TiO}_{2}(110)$. Surf Sci 395:292-306

21. Wang L-Q, Ferris KF, Skiba PX, Shultz AN, Baer DR, Engelhard MH (1999) Interactions of liquid and vapor water with stoichiometric and defective $\mathrm{TiO}_{2}(100)$ surfaces. Surf Sci 440:60-68

22. Schaub R, Thostrup P, Lopez N, Lægsgaard E, Stensgaard I, Nørskov JK, Besenbacher F (2001) Oxygen vacancies as active sites for water dissociation on rutile $\mathrm{TiO}_{2}(110)$. Phys Rev Lett $87: 266104$

23. Wendt S, Schaub R, Matthiesen J, Vestergaard EK, Wahlström E, Rasmussen MD, Thostrup P, Molina LM, Lægsgaard E, Stensgaard I, Hammer B, Besenbacher F (2005) Oxygen vacancies on $\mathrm{TiO}_{2}(110)$ and their interaction with $\mathrm{H}_{2} \mathrm{O}$ and $\mathrm{O}_{2}$ : a combined high-resolution STM and DFT study. Surf Sci 598:226-245

24. Bikondoa O, Pang CL, Ithnin R, Muryn CA, Onishi H, Thornton $\mathrm{G}$ (2006) Direct visualization of defect-mediated dissociation of water on $\mathrm{TiO}_{2}(110)$. Nat Mater 5:189-192

25. Zhang Z, Bondarchuk O, Kay BD, White JM, Dohnálek Z (2006) Imaging water dissociation on $\mathrm{TiO}_{2}(110)$ : evidence for inequivalent geminate OH groups. J Phys Chem B 110:21840-21845

26. Walle LE, Borg A, Johansson EMJ, Plogmaker S, Rensmo H, Uvdal P, Sandell A (2011) Mixed dissociative and molecular water adsorption on anatase $\mathrm{TiO}_{2}(101)$. J Phys Chem C 115:9545-9550

27. Kristoffersen HH, Hansen JØ, Martinez U, Wei YY, Matthiesen J, Streber R, Bechstein R, Lægsgaard E, Besenbacher F, Hammer $B$, Wendt $S$ (2013) Role of steps in the dissociative adsorption of water on rutile $\mathrm{TiO}_{2}(110)$. Phys Rev Lett 110:146101

28. Geng Z, Chen X, Yang W, Guo Q, Xu C, Dai D, Yang X (2016) Highly efficient water dissociation on anatase $\mathrm{TiO}_{2}(101)$. J Phys Chem C 120:26807-26813

29. Tan S, Feng H, Ji Y, Wang Y, Zhao J, Zhao A, Wang B, Luo Y, Yang J, Hou JG (2012) Observation of photocatalytic dissociation of water on terminal Ti Sites of $\mathrm{TiO}_{2}(110)-1 \times 1$ surface. J Am Chem Soc 134:9978-9985 
30. Zheng T, Wu C, Chen M, Zhang Y, Cummings PT (2016) A DFT study of water adsorption on rutile $\mathrm{TiO}_{2}(110)$ surface: the effects of surface steps. J Chem Phys 145:044702

31. Posternak M, Baldereschi A, Delley B (2009) Dissociation of water on anatase $\mathrm{TiO}_{2}$ nanoparticles: the role of undercoordinated Ti atoms at edges. J Phys Chem C 113:15862-15867

32. Shi H, Liu Y-C, Zhao Z-J, Miao M, Wu T, Wang Q (2014) Reactivity of the defective rutile $\mathrm{TiO}_{2}(110)$ surfaces with two bridgingoxygen vacancies: water molecule as a probe. J Phys Chem C 118:20257-20263

33. Castleman AW (2011) Cluster structure and reactions: gaining insights into catalytic processes. Catal Lett 141:1243-1253

34. Sauer J, Freund HJ (2015) Models in catalysis. Catal Lett 145:109-125

35. Gong Y, Zhou M, Andrews L (2009) Spectroscopic and theoretical studies of transition metal oxides and dioxygen complexes. Chem Rev 109:6765-6808

36. Zhai H-J, Wang L-S (2010) Probing the electronic structure of early transition metal oxide clusters: molecular models towards mechanistic insights into oxide surfaces and catalysis. Chem Phys Lett 500:185-195

37. Ramabhadran RO, Mann JE, Waller SE, Rothgeb DW, Jarrold CC, Raghavachari K (2013) New insights on photocatalytic $\mathrm{H}_{2}$ liberation from water using transition-metal oxides: lessons from cluster models of molybdenum and tungsten oxides. J Am Chem Soc 135:17039-17051

38. Yin S, Bernstein ER (2014) Experimental and theoretical studies of $\mathrm{H}_{2} \mathrm{O}$ oxidation by neutral $\mathrm{Ti}_{2} \mathrm{O}_{4,5}$ clusters under visible light irradiation. Phys Chem Chem Phys 16:13900-13908

39. Lang SM, Bernhardt TM, Kiawi DM, Bakker JM, Barnett RN, Landman U (2016) Cluster size and composition dependent water deprotonation by free manganese oxide clusters. Phys Chem Chem Phys 18:15727-15737

40. Fagiani MR, Song X, Debnath S, Gewinner S, Schöllkopf W, Asmis KR, Bischoff FA, Müller F, Sauer J (2017) Dissociative water adsorption by $\mathrm{Al}_{3} \mathrm{O}_{4}{ }^{+}$in the gas phase. $\mathrm{J}$ Phys Chem Lett 8:1272-1277

41. Cheng M-J, Chenoweth K, Oxgaard J, van Duin A, Goddard WA (2007) Single-site vanadyl activation, functionalization, and reoxidation reaction mechanism for propane oxidative dehydrogenation on the cubic $\mathrm{V}_{4} \mathrm{O}_{10}$ cluster. J Phys Chem C 111:5115-5127

42. Wu H, Wang L-S (1997) Electronic structure of titanium oxide clusters: $\mathrm{TiO}_{\mathrm{y}}(\mathrm{y}=1-3)$ and $\left(\mathrm{TiO}_{2}\right) n(n=1-4)$. J Chem Phys 107:8221-8228

43. Zhai H-J, Wang L-S (2007) Probing the electronic structure and band gap evolution of titanium oxide clusters $\left(\mathrm{TiO}_{2}\right)_{n}{ }^{-}$ $(n=1-10)$ using photoelectron spectroscopy. J Am Chem Soc 129:3022-3026

44. Gong Y, Zhang Q, Zhou M (2007) Matrix isolation infrared spectroscopic and theoretical study of group IV metal oxide clusters: $\mathrm{M}_{2} \mathrm{O}_{2}$ and $\mathrm{M}_{2} \mathrm{O}_{4}$. J Phys Chem A 111:3534-3539

45. Kim JB, Weichman ML, Neumark DM (2013) High-resolution anion photoelectron spectra of $\mathrm{TiO}_{2}^{-}, \mathrm{ZrO}_{2}^{-}$, and $\mathrm{HfO}_{2}^{-}$obtained by slow electron velocity-map imaging. Phys Chem Chem Phys 15:20973-20981

46. Kim JB, Weichman ML, Neumark DM (2014) Structural isomers of $\mathrm{Ti}_{2} \mathrm{O}_{4}$ and $\mathrm{Zr}_{2} \mathrm{O}_{4}$ anions identified by slow photoelectron velocity-map imaging spectroscopy. J Am Chem Soc 136:7159-7168

47. Deng H, Kerns KP, Guo B, Bell RC, Castleman AW (1998) The formation of $\left[\mathrm{TiO}\left(\mathrm{H}_{2} \mathrm{O}\right)_{n}\right]^{+}$cluster ions. Croat Chem Acta 71:1105-1116

48. Xu H-G, Li X-N, Kong X-Y, He S-G, Zheng W-J (2013) Interaction of $\mathrm{TiO}^{+}$with water: infrared photodissociation spectroscopy and density functional calculations. Phys Chem Chem Phys $15: 17126-17133$
49. Li R-Z, Xu H-G, Cao G-J, Xu X-L, Zheng W-J (2013) Interaction of $\mathrm{TiO}_{2}{ }^{-}$with water: photoelectron spectroscopy and density functional calculations. J Chem Phys 139:184303

50. Tsuchiya T, Whitten JL (2011) Theoretical study of the molecular and electronic structures of $\mathrm{TiO}_{4} \mathrm{H}_{4}, \mathrm{Ti}_{2} \mathrm{O}_{7} \mathrm{H}_{6}$, and $\mathrm{Ti}_{2} \mathrm{O}_{6} \mathrm{H}_{4}$. J Phys Chem C 115:1635-1642

51. Pandey LB, Aikens CM (2012) Theoretical investigation of the electrochemical mechanism of water splitting on a titanium oxide cluster model. J Phys Chem A 116:526-535

52. Çakir D, Gülseren O (2012) clusters and their interactions with water and transition metal atoms. J Phys 24:305301

53. Du H, De Sarkar A, Li H, Sun Q, Jia Y, Zhang R-Q (2013) Size dependent catalytic effect of $\mathrm{TiO}_{2}$ clusters in water dissociation. J Mol Catal A 366:163-170

54. Berardo E, Hu H-S, Shevlin SA, Woodley SM, Kowalski K, Zwijnenburg MA (2014) Modeling excited states in $\mathrm{TiO}_{2}$ nanoparticles: on the accuracy of a TD-DFT based description. J Chem Theory Comput 10:1189-1199

55. Rodríguez-Hernández F, Tranca DC, Szyja BM, van Santen RA, Martínez-Mesa A, Uranga-Piña L, Seifert G (2016) Water splitting on $\mathrm{TiO}_{2}$-based electrochemical cells: a small cluster study. J Phys Chem C 120:437-449

56. Muuronen M, Parker SM, Berardo E, Le A, Zwijnenburg MA, Furche F (2017) Mechanism of photocatalytic water oxidation on small $\mathrm{TiO}_{2}$ nanoparticles. Chem Sci 8:2179-2183

57. Valdés Á, Kroes G-J (2010) Cluster study of the photo-oxidation of water on rutile titanium dioxide $\left(\mathrm{TiO}_{2}\right)$. J Phys Chem C 114:1701-1708

58. Li Y-F, Liu Z-P (2011) Particle size, shape and activity for photocatalysis on titania anatase nanoparticles in aqueous surroundings. J Am Chem Soc 133:15743-15752

59. Meng Q-q, Wang J-g, Xie Q, Dong H-q, Li X-n (2011) Water splitting on $\mathrm{TiO}_{2}$ nanotube arrays. Catal Today 165:145-149

60. Berardo E, Zwijnenburg MA (2015) Modeling the water splitting activity of a $\mathrm{TiO}_{2}$ rutile nanoparticle. J Phys Chem C 119:13384-13393

61. Wang T-H, Fang Z, Gist NW, Li S, Dixon DA, Gole JL (2011) Computational study of the hydrolysis reactions of the ground and first excited triplet states of small $\mathrm{TiO}_{2}$ nanoclusters. J Phys Chem C 115:9344-9360

62. Fang Z, Dixon DA (2013) Computational study of $\mathrm{H}_{2}$ and $\mathrm{O}_{2}$ production from water splitting by small $\left(\mathrm{MO}_{2}\right)_{n}$ clusters $(\mathrm{M}=\mathrm{Ti}$, Zr, Hf). J Phys Chem A 117:3539-3555

63. Chen M, Straatsma TP, Dixon DA (2015) clusters, $n=1-4$. J Phys Chem A 119:11406-11421

64. Asmis KR, Brümmer M, Kaposta C, Santambrogio G, von Helden G, Meijer G, Rademann K, Wöste L (2002) Mass-selected infrared photodissociation spectroscopy of $\mathrm{V}_{4} \mathrm{O}_{10}{ }^{+}$. Phys Chem Chem Phys 4:1101-1104

65. Wolk AB, Leavitt CM, Garand E, Johnson MA (2014) Cryogenic ion chemistry and spectroscopy. Acc Chem Res 47:202-210

66. Asmis KR, Sauer J (2007) Mass-selective vibrational spectroscopy of vanadium oxide cluster ions. Mass Spectrom Rev 26:542-562

67. Asmis KR (2012) Structure characterization of metal oxide clusters by vibrational spectroscopy: possibilities and prospects. Phys Chem Chem Phys 14:9270-9281

68. Goebbert DJ, Meijer G, Asmis KR (2009) 10 K ring electrode trap-tandem mass spectrometer for infrared spectroscopy of mass selected ions. AIP Conf Proc 1104:22-29

69. Heine N, Asmis KR (2015) Cryogenic ion trap vibrational spectroscopy of hydrogen-bonded clusters relevant to atmospheric chemistry. Int Rev Phys Chem 34:1-34

70. Heine N, Asmis KR (2016) Cryogenic ion trap vibrational spectroscopy of hydrogen-bonded clusters relevant to atmospheric chemistry. Int Rev Phys Chem 35:507-507 
71. Schöllkopf W, Gewinner S, Junkes H, Paarmann A, von Helden G, Bluem H, Todd AMM (2015) The new IR and THz FEL facility at the Fritz Haber Institute in Berlin. Proc SPIE 9512:95121L

72. Geusic ME, Morse MD, O'Brien SC, Smalley RE (1985) Surface reactions of metal clusters I: the fast flow cluster reactor. Rev Sci Instrum 56:2123-2130

73. Brümmer M, Kaposta C, Santambrogio G, Asmis KR (2003) Formation and photodepletion of cluster ion-messenger atom complexes in a cold ion trap: Infrared spectroscopy of $\mathrm{VO}^{+}, \mathrm{VO}_{2}^{+}$, and $\mathrm{VO}_{3}$. J Chem Phys 119:12700-12703

74. Chai JD, Head-Gordon M (2008) Long-range corrected hybrid density functionals with damped atom-atom dispersion corrections. Phys Chem Chem Phys 10:6615-6620

75. Minenkov Y, Singstad A, Occhipinti G, Jensen VR (2012) The accuracy of DFT-optimized geometries of functional transition metal compounds: a validation study of catalysts for olefin metathesis and other reactions in the homogeneous phase. Dalton Trans 41:5526-5541

76. Frisch MJ, Trucks GW, Schlegel HB, Scuseria GE, Robb MA, Cheeseman JR, Scalmani G, Barone V, Mennucci B, Petersson GA, Nakatsuji H, Caricato M, Li X, Hratchian HP, Izmaylov AF, Bloino J, Zheng G, Sonnenberg JL, Hada M, Ehara M, Toyota K, Fukuda R, Hasegawa J, Ishida M, Nakajima T, Honda Y, Kitao O, Nakai H, Vreven T, Montgomery JA, Peralta JE, Ogliaro F, Bearpark M, Heyd JJ, Brothers E, Kudin KN, Staroverov VN, Kobayashi R, Normand J, Raghavachari K, Rendell A, Burant JC, Iyengar SS, Tomasi J, Cossi M, Rega N, Millam JM, Klene M, Knox JE, Cross JB, Bakken V, Adamo C, Jaramillo J, Gomperts R, Stratmann RE, Yazyev O, Austin AJ, Cammi R, Pomelli C, Ochterski JW, Martin RL, Morokuma K, Zakrzewski VG, Voth GA, Salvador P, Dannenberg JJ, Dapprich S, Daniels AD, Farkas Ö, Foresman JB, Ortiz JV, Cioslowski J, Fox DJ (2009) Gaussian 09, Revision C.01. Gaussian, Inc., Wallingford, CT

77. Song X, Fagiani MR, Debnath S, Gao M, Maeda S, Taketsugu T, Gewinner S, Schöllkopf W, Asmis KR, Lyalin A (2017) Excess charge driven dissociative hydrogen adsorption on $\mathrm{Ti}_{2} \mathrm{O}_{4}^{-}$. Phys Chem Chem Phys 19(34):23154-23161

78. Li S, Dixon DA (2008) Molecular structures and energetics of the $\left(\mathrm{TiO}_{2}\right)_{n}(n=1-4)$ clusters and their anions. J Phys Chem A 112:6646-6666
79. Yacovitch TI, Heine N, Brieger C, Wende T, Hock C, Neumark DM, Asmis KR (2013) Vibrational spectroscopy of bisulfate/sulfuric acid/water clusters: structure, stability, and infrared multiplephoton dissociation intensities. J Phys Chem A 117:7081-7090

80. Alecu IM, Zheng J, Zhao Y, Truhlar DG (2010) Computational thermochemistry: scale factor databases and scale factors for vibrational frequencies obtained from electronic model chemistries. J Chem Theory Comput 6:2872-2887

81. Irikura KK (2007) Experimental vibrational zero-point energies: diatomic molecules. J Phys Chem Ref Data 36:389-397

82. Asmis KR, Santambrogio G, Brummer M, Sauer J (2005) Polyhedral vanadium oxide cages: infrared spectra of cluster anions and size-induced d electron localization. Angew Chem Int Ed 44:3122-3125

83. Suda Y, Morimoto T (1987) Molecularly adsorbed $\mathrm{H}_{2} \mathrm{O}$ on the bare surface of $\mathrm{TiO}_{2}$ (rutile). Langmuir 3:786-788

84. Szczepankiewicz SH, Colussi AJ, Hoffmann MR (2000) Infrared spectra of photoinduced species on hydroxylated titania surfaces. J Phys Chem B 104:9842-9850

85. Finnie KS, Cassidy DJ, Bartlett JR, Woolfrey JL (2001) IR spectroscopy of surface water and hydroxyl species on nanocrystalline $\mathrm{TiO}_{2}$ films. Langmuir 17:816-820

86. Yamakata A, Ishibashi T, Onishi H (2002) Time-resolved infrared absorption studies of surface $\mathrm{OH}$ groups on $\mathrm{TiO}_{2}$ particles irradiated by UV pulses. Bull Chem Soc Jpn 75:1019-1022

87. Wang C-y, Groenzin H, Shultz MJ (2003) Molecular species on nanoparticulate anatase $\mathrm{TiO}_{2}$ film detected by sum frequency generation: trace hydrocarbons and hydroxyl groups. Langmuir 19:7330-7334

88. Nakamura R, Nakato Y (2004) Primary intermediates of oxygen photoevolution reaction on $\mathrm{TiO}_{2}$ (rutile) particles, revealed by in situ FTIR absorption and photoluminescence measurements. J Am Chem Soc 126:1290-1298

89. Fagiani MR, Knorke H, Esser TK, Heine N, Wolke CT, Gewinner S, Schöllkopf W, Gaigeot M-P, Spezia R, Johnson MA, Asmis KR (2016) Gas phase vibrational spectroscopy of the protonated water pentamer: the role of isomers and nuclear quantum effects. Phys Chem Chem Phys 18:26743-26754 